\title{
Método híbrido CONWIP/KANBAN: um estudo de caso
}

\section{Hybrid Method CONWIP/KANBAN: a case study}

\author{
Bruno Sereno' \\ Daniel Sant Anna da Silva ${ }^{1}$ \\ Dênis Gustavo Leonardo' \\ Mauro Sampaio²
}

\begin{abstract}
Resumo: Os sistemas de controle da produção geralmente são pontos de discussão nas principais literaturas da Engenharia de Produção. Pode-se dizer que sistema KANBAN é o método mais conhecido entre os profissionais da área para o controle e processamento de materiais no ambiente do chão de fábrica, devido à sua simplicidade e importância competitiva na concepção do sistema Toyota de produção. Analisando possíveis desvantagens apresentadas por este sistema, surge o CONWIP, demonstrando que $o$ KANBAN pode ser questionado em determinadas circunstâncias e mediante algumas variáveis do produto, demanda ou mesmo da produção. Investigar, comparar e apontar as vantagens, e as desvantagens do KANBAN, CONWIP e Método Híbrido CONWIP/KANBAN são o foco deste trabalho. A partir do estudo de caso de uma empresa com produção de componentes eletromecânicos para comando e monitoração de válvulas, caracterizada por pequenos lotes, alta customização e demanda incerta, discutem-se esses métodos, visando concluir, por meio dos resultados obtidos, os diferenciais da combinação do KANBAN e CONWIP no chamado Método Híbrido CONWIP/KANBAN.
\end{abstract}

Palavras-chave: KANBAN. CONWIP. Método Híbrido CONWIP/KANBAN.

\begin{abstract}
Production control systems have been widely discussed in the Production Engineering literature. The KANBAN system is the most known among professionals for the control and processing of materials in the shop floor environment due to its simplicity and competitive significance in the design of the Toyota production system. Analyzing possible disadvantages presented by this system, the CONWIP demonstrates that the KANBAN can be questioned in certain circumstances and upon certain variables of the product, demand, or production. The objective of this research is to Investigate, compare, and point out the advantages and disadvantages of KANBAN, CONWIP, and the CONWIP/KANBAN Hybrid Method. Based on the case study in a company that manufactures electromechanical components for valve monitoring and control, characterized by small lots, high customization, and uncertain demand, these methods were discussed in order to show, through the results, the differential combination of KANBAN and CONWIP in the CONWIP/KANBAN Hybrid method.
\end{abstract}

Keywords: KANBAN. CONWIP. CONWIP/KANBAN Hybrid Method.

\section{Introdução}

O estudo de sistemas de planejamento e controle da produção é um dos assuntos mais discutidos na área de engenharia da produção (FERNANDES; GODINHO FILHO, 2010). Existem vários sistemas de coordenação de ordens de produção e compra (SCO) conhecidos, tais como KANBAN, CONWIP, Método Híbrido CONWIP/KANBAN, entre outros (FERNANDES; GODINHO FILHO, 2007). O objetivo de um SCO é alcançar elevado nível de serviço ao cliente, sem aumentar os estoques; porém, escolher o sistema mais adequado para a produção de itens customizados na prática ainda é um desafio (LAGE JUNIOR; GODINHO FILHO, 2008).

O sistema mais conhecido é o KANBAN (OHNO, 1997; SHINGO, 1996), no qual a liberação de ordens de produção é feita por meio de sinalizadores (cartões) que limitam o estoque em processo do sistema. No entanto, o sistema KANBAN é lento para responder às mudanças de demanda. Outro sistema conhecido é o CONWIP - Constant Work-In-Process (SPEARMAN; WOODRUFF; HOPP, 1990), que utiliza um único tipo de cartão para controlar a quantidade total de estoque

\footnotetext{
${ }^{1}$ Engenheiro de Produção do Centro Universitário da FEI, Av. Humberto de Alencar Castelo Branco, 3972, CEP 09850-901, São Bernardo do Campo, SP, Brasil, e-mail: brunosereno@hotmail.com; daniel.santanna@ymail.com; d.leonardo@hotmail.com

${ }^{2}$ Professor do Programa de Mestrado em Engenharia Mecânica: área produção pelo Centro Universitário da FEI, Av. Humberto de Alencar Castelo Branco, 3972, CEP 09850-901, São Bernardo do Campo, SP, Brasil, e-mail: msampaio@ fei.edu.br
}

Recebido em 3/2/2011 - Aceito em 12/7/2011

Suporte financeiro: Nenhum. 
em processo (WIP) permitido na linha de produção; e esse sistema é mais ágil em resposta às mudanças de demanda. A combinação desses sistemas deu origem a um sistema de produção chamado Método Híbrido CONWIP/KANBAN (BONVIK; COUCH; GERSHWIN, 1997). Entretanto, ainda pouco se sabe dos possíveis ganhos proporcionados pela adoção desses métodos, principalmente quando se refere à produção de pequenos lotes com alta customização e demanda incerta. Existem outros SCO derivados do KANBAN (LAGE JUNIOR; GODINHO FILHO, 2008), mas este trabalho focará exclusivamente os métodos acima citados.

O objetivo deste trabalho é entender, descrever e investigar os métodos de controle da produção KANBAN, CONWIP e Método Híbrido CONWIP/ $K A N B A N$, procurando identificar as principais dificuldades e falhas do processo de implantação, o ganho na produtividade e, principalmente, o aumento no nível de serviço em uma empresa com produção de pequenos lotes com alta customização e demanda incerta, demonstrando que tais aspectos são de alta relevância no desempenho dos sistemas de controle. Foram desenvolvidos todos os conceitos relacionados à KANBAN, CONWIP e Método Híbrido CONWIP/ $K A N B A N$, no intuito de explorar esses processos e descobrir qual melhor se adequou à empresa em estudo.

Em síntese, pretende-se responder às seguintes questões de pesquisa: Quais variáveis têm impacto na seleção do método de controle de produção, visando ao máximo nível de serviço? Quando o Método Híbrido CONWIP/KANBAN é mais adequado nos sistemas produtivos? Quais os resultados obtidos com a aplicação do Método Híbrido CONWIP/KANBAN numa empresa de produtos customizados, pequenos lotes e demanda incerta?

Por meio da análise em profundidade do caso em um fabricante de acessórios eletromecânicos para comando e monitoração de válvulas, demonstra-se que o Método Híbrido CONWIP/KANBAN proporciona altos níveis de serviço com expressivas reduções de estoque.

Este artigo está subdividido em cinco seções. A primeira relata a evolução histórica dos sistemas de controle de produção. A segunda explica os conceitos básicos envolvidos neste estudo. A parte seguinte discute os artigos publicados sobre o tema abordado. Em seguida é apresentado o estudo de caso utilizado no trabalho. A conclusão encontra-se na quinta e última seção.

\section{Revisão da literatura}

A melhoria do desempenho de processos no ambiente das indústrias de manufatura é um problema clássico enfrentado pelos dirigentes industriais (FERNANDES; GODINHO FILHO, 2010). Na década de 1980, iniciou-se o interesse mundial pelo sistema puxado de produção da indústria japonesa, denominado KANBAN, e consagrado, nos anos 90, pela equipe de pesquisadores do Massachusetts Institute of Technology (MIT), como o modelo de produção mais competitivo entre os adotados pelas empresas automobilísticas em todo o mundo.

No entanto, com o passar dos anos, observou-se que o KANBAN, apesar dos inúmeros benefícios extraídos, não se comportava de forma satisfatória quando submetido à mix variável de produtos que apresentam demanda não estável. Nesse caso, os resultados foram altos níveis de estoque, redução da taxa de produção, aumento dos custos de armazenagem e nível de serviço insatisfatório.

Dez anos depois, foi proposto o método CONWIP (SPEARMAN et al., 1990) que, segundo os autores, solucionava as deficiências observadas até então no KANBAN.

Da mesma forma, a partir dos resultados da experiência com a aplicação desses dois métodos separados, foi proposto o Método Híbrido CONWIP/ KANBAN (BONVIK et al., 1997), visando incorporar seus respectivos aspectos positivos, cuja combinação geraria um aumento expressivo no nível de serviço ao cliente.

\subsection{KANBAN}

O KANBAN é o mais conhecido desses sistemas por ser um sistema de controle da produção desenvolvido no Japão e que funciona entre estações de trabalho consecutivas. Sua principal função é regular os níveis de estoque, mantendo-os o mais baixo possível sem comprometer a produção. Quando o estoque intermediário da estação de trabalho seguinte está baixo, o KANBAN permite que a produção se inicie na estação anterior.

Segundo Boonlertvanich (2005), existem muitas versões de controle $K A N B A N$, por exemplo, de cartão único, de dois cartões, etc. A comparação dos diferentes sistemas de KANBAN pode ser encontrada em Mukcstadt e Tayur (1995). A Figura 1 mostra uma linha de produção de dois estágios de um único produto controlada pelo sistema KANBAN.

A fila Bi é o buffer de saída do estágio i contendo as duas partes acabadas e a marcação da fase i do $K A N B A N$. A fila Ki contém o estágio i do KANBAN. O movimento KANBAN é mostrado pela linha traço-ponto.

Quando o sistema está em seu estado inicial, o buffer Bi contém a quantidade ki de peças acabadas do estágio i e cada parte com uma fase-i do KANBAN ligado a ela, e todos os outros buffers estão vazios. $\mathrm{O}$ sistema de controle KANBAN funciona da seguinte forma: a demanda do cliente chega ao sistema na fila $\mathrm{D}$, solicitando a liberação de um produto acabado 


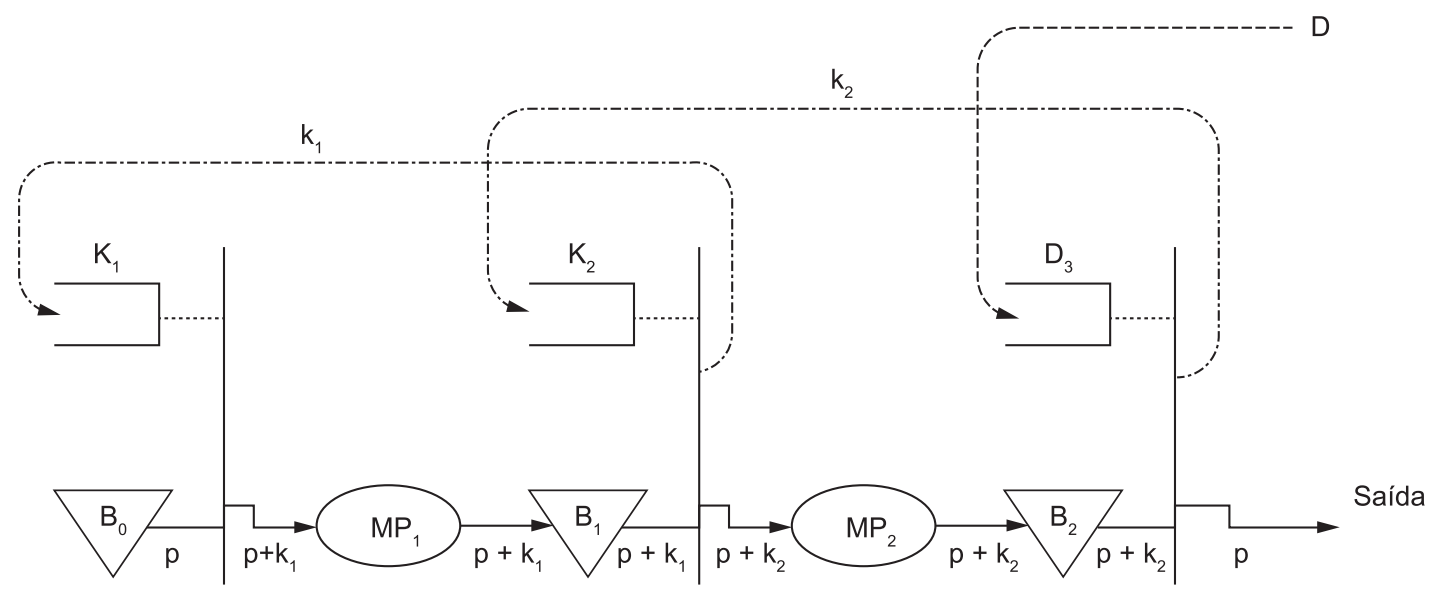

Matéria prima

Produto final

Figura 1. Linha de Produção de dois estágios controlada pelo sistema KANBAN. Fonte: Boonlertvanich (2005, p. 19).

a partir de $\mathrm{B}_{2}$ para o cliente. Nesse momento, há duas possibilidades:

Se há peça disponível em $\mathrm{B}_{2}$ (que inicialmente é o caso), esta é liberada para o cliente depois de liberar o estágio 2 do $K A N B A N$, que foi anexado a ele. Este cartão de KANBAN é transferido ao $\mathrm{K}_{2}$, levando consigo um sinal de demanda para a produção de uma nova peça acabada no estágio 2 .

Se nenhuma peça acabada está disponível em $\mathrm{B}_{2}$, a demanda está em espera e aguarda em $\mathrm{D}$ até que uma nova peça completa da fase 2 chegue em $\mathrm{B}_{2}$. A parte recém-terminada será lançada para o cliente imediatamente e o KANBAN ligado a ela irá transferir para a fila $\mathrm{K}_{2}$ imediatamente também.

Assim que o sinal do KANBAN chega em $\mathrm{K}_{2}$, ele autoriza a produção de uma nova peça no estágio 2. Novamente, neste momento, duas coisas podem acontecer: se há peça disponível em $\mathrm{B}_{1}$ com cartão $K A N B A N$ do estágio 1 anexado a ela, o cartão é instantaneamente retirado e anexado o cartão KANBAN do estágio 2. Ao mesmo tempo esta peça é liberada para produção em $\mathrm{MP}_{2}$ e o KANBAN do estágio 1 é transferido para $\mathrm{K}_{1}$, que autoriza a liberação de matéria-prima bruta de $\mathrm{P}_{0}$ para $\mathrm{MP}_{1}$. Mas, se nenhuma peça está disponível em $\mathrm{B}_{1}, \mathrm{o} K A N B A N$ do estágio 2 aguarda em $\mathrm{K}_{2}$ até que uma nova peça chegue em $\mathrm{B}_{1}$.

Desta forma, as informações de demanda do cliente são transferidas por um sinal KANBAN no estágio anterior até chegar ao estoque de matéria-prima. Se, em algum estágio i, não há peça disponível no Bi, não há transferência de KANBAN para o estágio anterior e, então, a informação de demanda é temporariamente interrompida e retomada somente quando uma parte voltar a ficar disponível em Bi. Assim, a filosofia do controle $K A N B A N$ consiste na transferência da informação de demanda para o estágio anterior somente quando há peça disponível na fase posterior.
O controle KANBAN é um mecanismo de controle simples que depende apenas de um parâmetro por etapa, ou seja, ki, i $=1, \ldots \mathrm{N}$. Esses parâmetros influenciam tanto a liberação das peças acabadas para o estágio seguinte quanto a transferência de informação de demanda para o estágio anterior.

Em um sistema KANBAN, a transferência de uma peça acabada de Bi para MPi é totalmente sincronizada com a transferência de demanda de $\mathrm{Ki}+1$ (ou D se $\mathrm{i}=\mathrm{N}$ ) em Ki. O invariante do mecanismo KANBAN de cada etapa, conforme Boonlertvanich (2005), pode ser expressa como segue (Equação 1):

$$
\begin{aligned}
& \text { NQ }(\mathrm{Ki})+\mathrm{NQ}(\mathrm{MPi})+ \\
& +\mathrm{NQ}(\mathrm{Bi})=\mathrm{ki}, \mathrm{i}=1, \ldots, \mathrm{N}
\end{aligned}
$$

Isso implica que tanto o WIP como o número de peças acabadas em cada etapa i são delimitados por ki.

\subsection{CONWIP}

O CONWIP é um sistema híbrido de controle da produção, que pode ser considerado puxado pelo final da linha e empurrado do início ao final da linha. Segundo Spearman et al. (1990), como no KANBAN, o CONWIP limita a quantidade de WIP no sistema, com o benefício de reduzir custos e lead time.

Boonlertvanich (2005) afirma que, quando o nível de WIP é alcançado, não são liberadas novas ordens antes que as atuais saiam do sistema. Isso ocorre somente em resposta à demanda de Produtos Acabados (PA). Uma linha CONWIP pode ser vista como uma célula controlada por KANBAN único que engloba todas as fases.

A Figura 2 mostra o modelo de rede de filas de um produto único com uma política de controle CONWIP com duas etapas de fabricação em série. Mesmo que 
existam duas fases elaboradas, o controle da produção via CONWIP é executado somente no momento da entrada e o buffer intermédio, $B_{1}$, não tem qualquer ação de controle. O CONWIP de fato é considerado como um controle de fase única.

MP1 e MP2 representam fases de produção 1 e 2, enquanto $\mathrm{B}_{0}$ representa buffer de matériasprimas. Bi é o buffer de saída do estágio I. Fila MPi é a quantidade total de partes que foi liberada para a fase i. A fila D contém a demanda e a fila $\mathrm{C}$ contém cartões/ordens CONWIP.

Quando o sistema está em seu estado inicial, que é antes de todas as demandas chegarem ao sistema, o buffer $\mathrm{B}_{1}$ está vazio. Apenas o buffer $\mathrm{B}_{2}$ contém $\mathrm{C}$ peças acabadas anexadas com os cartões CONWIP.

O sistema CONWIP funciona da seguinte forma: quando a demanda do cliente chega, o sistema solicita a liberação de um produto acabado a partir de $\mathrm{B}_{2}$ para o cliente. Neste momento há duas possibilidades: se uma parte está disponível em B2 (que inicialmente é o caso), ela é liberada imediatamente para o cliente e o cartão CONWIP é desanexado da peça e transferido para C. Caso contrário, a demanda fica em espera e aguarda em D até uma nova peça acabada. Para os outros estágios, o funcionamento será como em um sistema empurrado, peças movendo para o final da linha sem qualquer bloqueio.

O controle CONWIP é um mecanismo de controle muito simples, que depende apenas de um parâmetro para todo o sistema, a quantidade de CONWIP, C. Ela influencia tanto a transferência de peças acabadas ao final da linha quanto a transferência de demanda no início do sistema. Não há transferência de demanda entre cada etapa, exceto a última e a primeira.

A capacidade de produção ou a taxa máxima de produção do sistema é afetada apenas pela quantidade de cartões CONWIP, C. Conforme Boonlertvanich (2005), a quantidade total de peças no sistema é determinada por $\mathrm{C}$ e pode ser expressa como segue (Equação 2):

$$
\begin{aligned}
& \text { NQ (C) }+\Sigma \text { NQ (MPI) }+ \\
& +\Sigma \text { NQ }(\mathrm{Bi})=\mathrm{C}, \mathrm{i}=1, \ldots, \mathrm{N}
\end{aligned}
$$

Se ocorrer uma falha em um estágio de uma linha CONWIP, a quantidade de material do lado direito da linha (em direção a D) vai ser gradualmente liberada do sistema pelo processo de procura. A demanda desencadeia o processo para a liberação de novas peças para o início do sistema. Quando todos os cartões CONWIP acumularem-se na frente da máquina que falhou, o lançamento de novas ordens de produção para o sistema irá parar.

CONWIP pode ser implantando por meio de um cartão único, associando-o a uma peça e autorizando a sua presença no sistema. Sempre que uma peça sai do estoque de produto acabado, o seu cartão é separado e enviado para o estágio inicial de produção, que autoriza a entrada de outra peça no sistema. Todas as outras etapas do processo estão sempre autorizadas a trabalhar enquanto houver peças liberadas no sistema. Sendo assim, não é necessário passar o cartão a estas máquinas.

\subsection{Método Híbrido CONWIP/KANBAN}

Segundo Bonvik et al. (1997), em alguns casos, o acúmulo de estoque no sistema CONWIP é excessivo. Por exemplo, se algum estágio é o gargalo do processo, não haverá nenhum acúmulo de peças em sua saída por muito tempo. Se os estágios anteriores ao gargalo são relativamente rápidos e confiáveis, deve-se optar por limitar esse nível de estoque antes que o máximo seja atingido. Por isso, Bonvik et al. (1997) propuseram a política de controle de produção chamada de Método Híbrido CONWIP/KANBAN, no

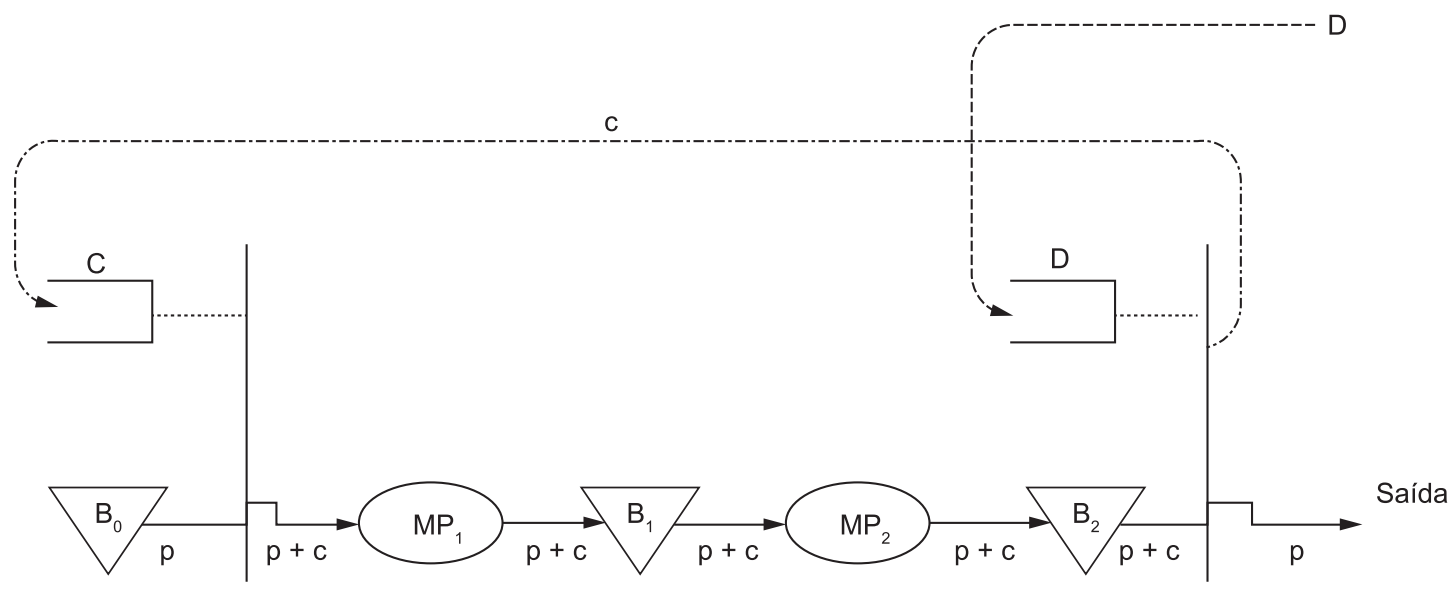

Matéria prima

Figura 2. Modelo de rede de filas de um produto único CONWIP. Fonte: Boonlertvanich (2005, p. 14). 
qual o controle CONWIP é completado com células secundárias controladas por KANBAN. Esse sistema detecta problemas na linha e bloqueia o lançamento de peças para produção, se essas não puderem ser processadas no futuro.

Boonlertvanich (2005) afirma que o Método Híbrido CONWIP/KANBAN caracteriza-se pelo objetivo de solucionar esta questão da seguinte forma: a informação de demanda de produto acabado é propagada diretamente ao início da cadeia para autorizar o primeiro estágio de produção por meio do método CONWIP e, para evitar o acúmulo de estoque na entrada do estágio caracterizado como gargalo, este é limitado em cada estágio pelo KANBAN.

A Figura 3 mostra um modelo de linha de produção com dois estágios de um único produto controlado via Método Híbrido CONWIP/KANBAN. Bi são os buffers de saída dos estágios i, contendo peças acabadas, cartões de KANBAN e CONWIP dos estágios i. A fila Ki contém cartões $K A N B A N$ do estágio i e a fila $\mathrm{C}$ contém os cartões de $C O N W I P$. O movimento dos cartões KANBAN e CONWIP é identificado pela linha traço-ponto.

Quando o sistema está em seu estado inicial, o estoque $\mathrm{B}_{2}$ contém peças acabadas do estágio $\mathrm{k}_{2}$, cada peça contendo um cartão $K A N B A N$ do estágio $\mathrm{k}_{2} \mathrm{e}$ um cartão de $C O N W I P$ anexado a ela. $\mathrm{O}$ estoque $\mathrm{B}_{1}$ contém peças acabadas de $\mathrm{C}$ - ( $\mathrm{k}_{2}$ do estágio 2$)$, cada peça contendo um cartão $K A N B A N$ do estágio $2 \mathrm{e}$ um cartão $C O N W I P$. Há $\mathrm{k}_{1}-\left(\mathrm{C}_{-} \mathrm{k}_{2}\right)$ cartões $K A N B A N$ na fila $\mathrm{K}_{1}$. Todos os outros estoques estão vazios. Parte-se do pressuposto de que a soma de todos os cartões $K A N B A N$ seja maior ou igual ao nível de cartões de CONWIP.

O Método Híbrido CONWIP/KANBAN funciona da seguinte forma: quando a informação de demanda chega ao sistema, ela se aloca em $\mathrm{D}$ para solicitar a liberação de uma peça acabada em $\mathrm{B}_{2}$ para o cliente. Nesse momento, há duas possibilidades: se uma peça está disponível em $\mathrm{B}_{2}$, que é inicialmente o caso, ela é liberada ao cliente depois de liberar o cartão KANBAN do estágio 2 e o cartão $C O N W I P$ que estão anexados a ela. $\mathrm{O} K A N B A N\left(\mathrm{k}_{2}\right)$ é transferido a $\mathrm{K}_{2}$, carregando com ele o sinal de necessidade de produção de novas peças acabadas do estágio 2. O cartão CONWIP "c" será transferido ao estoque $\mathrm{C}$, autorizando a liberação de matéria-prima para o sistema.

Se não há peças disponíveis em $\mathrm{B}_{2}$, a informação de demanda é interrompida e aguarda em $\mathrm{D}$ até que a peça seja finalizada no estágio 2 e chegue em $\mathrm{B}_{2}$. Após a chegada desta peça em $\mathrm{B}_{2}$, ela é instantaneamente transferida ao cliente e seu cartão $K A N B A N \mathrm{k}_{2}$ também para $\mathrm{K}_{2}$. Assim que o cartão chega em $\mathrm{K}_{2}$, ele autoriza a produção de uma nova peça no estágio $\mathrm{K}_{2}$. Novamente, nesse momento, há duas possibilidades: se a peça com $\mathrm{K}_{1}$ está disponível em $\mathrm{B}_{1}$, ela é imediatamente transferida para o estágio 2 (MP2) e seu cartão k1 é transferido para $\mathrm{K}_{1}$, autorizando a produção de uma nova peça no estágio 1 . Se não há disponibilidade de peças em $\mathrm{B}_{1}$, o cartão $\mathrm{k}_{2}$ espera em $\mathrm{K}_{2}$ até que uma nova peça chegue em $B_{1}$.

Uma exceção seria quando tanto o sinal KANBAN quanto o sinal $C O N W I P$ chegam à fila $\mathrm{K}_{1}$ por $K A N B A N$ ou a $\mathrm{C}$ por $C O N W I P$; é necessário esperar o outro sinal para liberação de matéria-prima para produção no estágio 1. Dessa forma, a informação de demanda do cliente é transferida para a célula anterior por KANBAN e para a fase inicial (liberação de matériaprima) por $C O N W I P$. Se, em algum estágio i, não há disponibilidade de peças em Bi, não há transferência do cartão $K A N B A N$ ki para a célula anterior, e a autorização para liberar uma peça é temporariamente

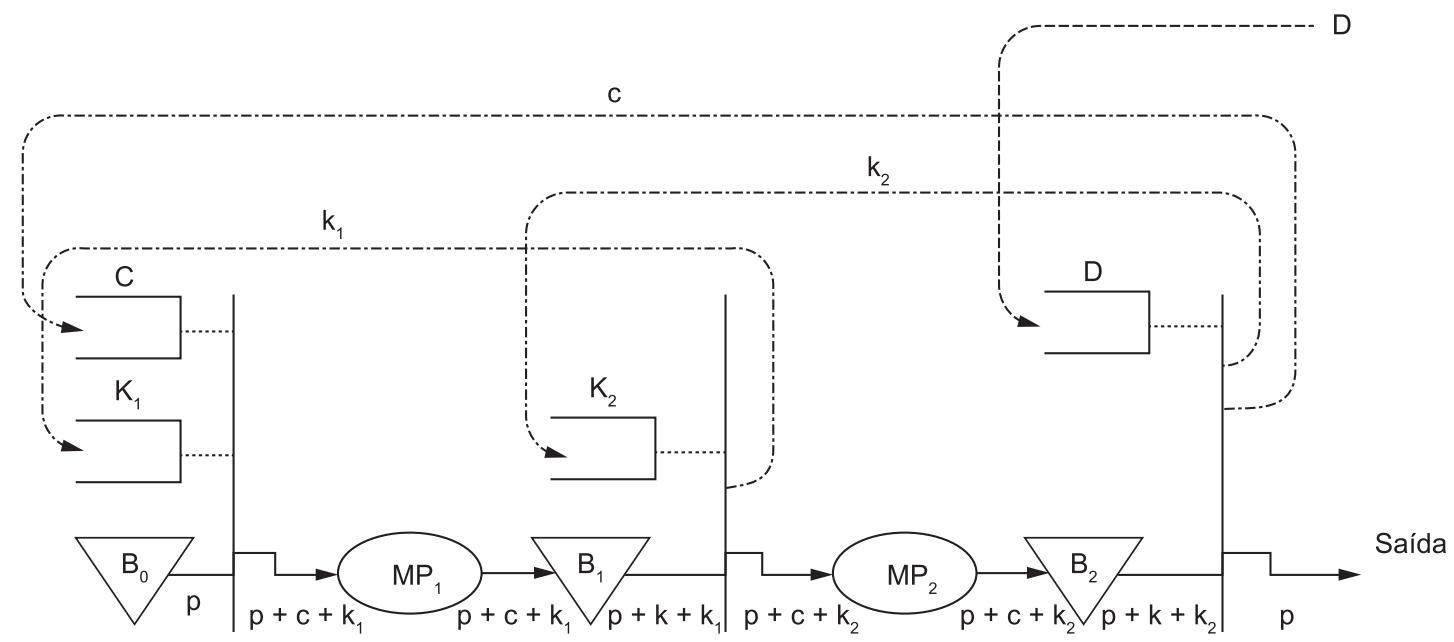

Matéria prima

Figura 3. Modelo de linha de produção com dois estágios de um único produto, controlado via sistema Método Híbrido CONWIP/KANBAN. Fonte: Boonlertvanich (2005, p. 21). 
interrompida e retomada quando novamente houver uma peça disponível em Bi. Além disso, o controle por meio de CONWIP irá limitar a quantidade total de work-in-process no sistema, pois, mesmo que haja um cartão $K A N B A N$ livre na primeira fase, as matérias-primas não serão liberadas até que o total de WIP esteja abaixo do limite fixado pelo CONWIP.

Segundo Boonlertvanich (2005), o Método Híbrido CONWIP/KANBAN é um mecanismo de controle que depende apenas de um parâmetro por estágio, chamado ki, e um parâmetro adicional para o sistema inteiro, C. O número de cartões KANBAN e CONWIP influencia nas duas extremidades do sistema: na transferência de peças acabadas ao cliente ou ao próximo estágio e na transferência de demandas para os estágios anteriores.

Para ilustrar a melhoria do Método Híbrido, apresenta-se o resultado obtido por simulações computacionais feitas por Bonvik et al. (1997) no MIT Massachusetts Institute of Technology. A Figura 4 mostra os resultados obtidos nesta simulação e conclui-se que, para qualquer meta estabelecida de nível de serviços, o Método Híbrido CONWIP/ $K A N B A N$ apresenta menor nível de estoque quando comparado à melhor política de KANBAN.

\subsection{Pesquisas específicas sobre o método CONWIP/KANBAN}

$\mathrm{Na}$ Tabela 1 se encontram os principais artigos publicados sobre o Método Híbrido CONWIP/ $K A N B A N$. A seguir é realizada uma breve síntese de cada um deles, ressaltando suas contribuições e os principais pontos relacionados ao tema desta pesquisa.

Para Bonvik et al. (1997), o método Híbrido CONWIP/KANBAN pode ser definido como um sistema de controle da produção no qual a informação

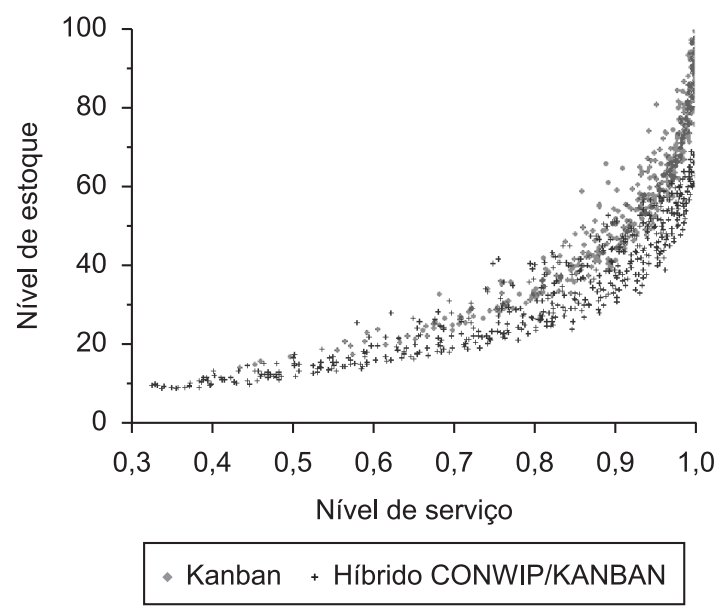

Figura 4. Nível de serviço por nível de estoque. KANBAN indicado por losangos Método Híbrido CONWIP/KANBAN em sinais +. Fonte: Bonvik (1997). de demanda é propagada ao primeiro estágio da linha, os estoques intermediários são controlados por sinalizadores e o estoque total em processo é limitado (CONWIP). Por meio de estudos de simulação computacional, buscou-se comparar os resultados obtidos em relação ao nível de serviço e à quantidade de estoque em processo quando submetidos a variações de demanda e a mix variável de produtos. Dentre as premissas consideradas no trabalho de Bonvik et al. (1997), destacam-se: linha de produção de 4 estágios, produção de uma peça por vez, tempo de movimentação nulo e transmissão imediata da informação dos cartões. O resultado da pesquisa dos autores demonstra que é possível reduzir os estoques em até $20 \%$, quando comparado ao sistema KANBAN, mantendo-se o mesmo nível de serviço. Também em seu estudo, Bonvik et al. (1997) constatam que este método reage de maneira superior às mudanças de demanda, isto é, o nível de estoque acompanha a variação de demanda: se a demanda diminui o estoque é menor. Por questões de limitação computacional, vale ressaltar que o estudo de Bonvik et al. (1997) considerou que qualquer demanda não suprida pelo estoque de produto acabado é considerada perdida.

Gaury, Pierreval e Kleijnen (2000), por sua vez, propõem uma metodologia para seleção de um sistema de produção puxado para um fluxo de linhas de um único produto. Foi mostrado um sistema genérico que combina as características do KANBAN, CONWIP e Método Híbrido CONWIP/ $K A N B A N$. A metodologia é baseada na determinação do número de cartões no sistema genérico por meio de simulação no sistema. A principal vantagem dessa abordagem é que, para uma dada linha de produção, um único procedimento de otimização é suficiente para proporcionar a melhor configuração da estratégia de controle. Foram estudados três exemplos baseados em linhas de produção, com seis, oito e dez máquinas. Os resultados mostram que as melhores estratégias são os sistemas híbridos. Foi ressaltado que o desempenho de tais sistemas híbridos é principalmente devido ao $C O N W I P$ e à adição do KANBAN, que melhora ainda mais o desempenho.

Já Kleijnen e Gaury (2003) aplicaram uma abordagem interessante baseada em análise de risco para julgar a robustez do sistema. Eles combinaram eventos discretos da simulação, otimização heurística, análise de risco e bootstrapping, e chegaram a uma posição diferente de ranking dos SCO em comparação com um estudo anterior de Gaury (2000), em que o risco não é considerado. Kleijnen e Gaury (2003) atestam que o sistema Híbrido CONWIP/KANBAN tem um desempenho superior quando robustez e riscos são considerados.

Boonlertvanich (2005) propõe um novo Método Híbrido de controle da produção, similar ao Método Híbrido CONWIP/KANBAN, denominado Kanban 
Tabela 1. Artigos acadêmicos.

\begin{tabular}{|c|c|c|c|c|}
\hline Autor & Descrição & KANBAN & CONWIP & Método híbrido \\
\hline $\begin{array}{l}\text { Bonvik et al. } \\
\text { (1997) }\end{array}$ & $\begin{array}{l}\text { Comparação de mecanismos de } \\
\text { controle de produção em linha. }\end{array}$ & $\mathrm{X}$ & $\mathrm{X}$ & \\
\hline $\begin{array}{l}\text { Gaury, Pierreval e } \\
\text { Kleijnen (2000) }\end{array}$ & $\begin{array}{l}\text { Metodologia para seleção de um sistema } \\
\text { de produção puxado para um fluxo de } \\
\text { linhas de um único produto. }\end{array}$ & $\mathrm{X}$ & $\mathrm{X}$ & $\mathrm{X}$ \\
\hline Kleijnen e & Compararam os sistemas & & $X$ & $\mathrm{X}$ \\
\hline Gaury (2003) & $\begin{array}{l}K A N B A N, C O N W I P, C O N W I P / \\
K A N B A N \text {, e Kanban genérico. }\end{array}$ & & & \\
\hline $\begin{array}{l}\text { Boonlertvanich } \\
(2005)\end{array}$ & $\begin{array}{l}\text { Proposição de um novo método de controle } \\
\text { chamado Extended CONWIP KANBAN. }\end{array}$ & $\mathrm{X}$ & $\mathrm{X}$ & $\mathrm{X}$ \\
\hline $\begin{array}{l}\text { Geraghty e } \\
\text { Heavey (2005) }\end{array}$ & $\begin{array}{l}\text { Uma comparação e revisão das } \\
\text { estratégias dos sistemas de } \\
\text { produção híbridos e puxados. }\end{array}$ & $\mathrm{X}$ & $\mathrm{X}$ & $\mathrm{X}$ \\
\hline Barco e & Comparam os sistemas de controle & & $\mathrm{X}$ & $\mathrm{X}$ \\
\hline Villela (2008) & $\begin{array}{l}\text { CONWIP e o Método Híbrido CONWIP/ } \\
\text { KANBAN, em uma empresa fornecedora de } \\
\text { acessórios para a indústria automobilística. }\end{array}$ & & & \\
\hline $\begin{array}{l}\text { Sharma e } \\
\text { Agrawal (2009) }\end{array}$ & $\begin{array}{l}\text { Comparam os sistemas } \\
K A N B A N, C O N W I P \text { e Híbrido. }\end{array}$ & $X$ & $\mathrm{X}$ & $\mathrm{X}$ \\
\hline
\end{tabular}

Fonte: Os autores.

estendido. A autora faz uma revisão conceitual dos principais métodos de controle e planejamento da produção, utilizados em sistemas puxados, desde o MRP, KANBAN, passando pelo KANBAN, Controle Estoque-Base, CONWIP, CONWIP/KANBAN, até chegar à proposição da Kanban estendido. A partir de pressupostos delimitados inicialmente, é definido o nível de serviço, como o parâmetro de medição principal em cada um dos sistemas e, com o apoio de um software de simulação, são demonstrados os resultados apresentados em cada um dos sistemas. As variações de projeto/produto e suas respectivas demandas foram preponderantes nesta etapa.

Geraghty e Heavey (2005), em um exaustivo estudo, comparam os SCO puxados e os SCO híbridos por meio de técnicas de simulação. Eles concluem que o Método Híbrido CONWIP/Kanban foi consistentemente melhor do que todos os outros SCO, e que o Kanban tradicional foi consistentemente o pior. O domínio do Método Híbrido CONWIP/ Kanban em relação ao Kanban foi significativo, entretanto, em comparação com as outras abordagens, seu domínio foi marginal, especialmente no caso de baixa capacidade do sistema produtivo. Os autores argumentam que a predominância do Sistema Híbrido CONWIP/KanbaN é devida à comunicação direta de informações de demanda para a primeira etapa de produção. Um desempenho semelhante ao sistema Método Híbrido CONWIP/Kanban foi mostrado pelo Sistema KANBAN estendido. A principal diferença foram os níveis de estoque, o Sistema KANBAN estendido tende a reter mais WIP que os sistemas
Método Híbrido CONWIP/Kanban, que tende a reter mais o inventário na forma de produtos acabados.

Barco e Villela (2008) também apresentam e comparam os sistemas de controle CONWIP e o Método Híbrido CONWIP/KANBAN. O trabalho foi resultado da necessidade inicial de melhorar o funcionamento do sistema de produção de uma empresa fornecedora de acessórios para a indústria automobilística que apresentava problemas no funcionamento do sistema de produção. Mais da metade das paradas na produção eram causadas pelo mau planejamento do setor de solda, em que se utilizava um sistema híbrido de controle da produção. Os autores delineiam as diferenças existentes entre os sistemas de produção empurrada e puxada.

Conclui-se, a partir dessa revisão bibliográfica, que os métodos KANBAN, CONWIP e método Híbrido $C O N W I P / K A N B A N$ são de interesse dos pesquisadores, mas a maioria dos estudos é dedicada à simulação; poucos estudos de casos foram investigados para avaliação na prática dos benefícios encontrados.

\section{Metodologia}

Como o propósito desta pesquisa é investigar os resultados alcançados pela aplicação do Método Híbrido CONWIP/KANBAN, fenômeno contemporâneo sobre o qual o pesquisador não tem nenhum controle, a metodologia indicada por diversos autores (EISENHARDT, 1989; ELLRAM, 1996; YIN, 2003) é o estudo de caso. O conhecimento disponível sobre o fenômeno de interesse é escasso, observado pelo baixo índice de publicações sobre o assunto. 
Nesse caso, a pesquisa exploratória é essencial para desenvolver e prover novas ideias e descobertas.

De acordo com Yin (2003), existem dois tipos de estudo de caso: o caso único, em que a unidade de análise é um caso apenas; e os estudos multicasos, em que vários casos são analisados de forma a permitir o estabelecimento de comparações.

Yin (2003) também classifica o estudo de caso único em holístico ou incorporado. O tipo holístico possui uma unidade de análise sendo considerada em determinado contexto. Já o incorporado possui mais de uma unidade de análise para cada caso, ou seja, existem subunidades de análise.

Yin (2003) estabelece outra classificação do estudo de caso quanto ao objetivo da pesquisa: descritivo - descreve o fenômeno dentro de seu contexto; exploratório - trata com problemas pouco conhecidos, objetivando definir hipóteses ou proposições para futuras pesquisas; explanatório possui o intuito de explicar relações de causa e efeito a partir de uma teoria.

Assim, de acordo com os parâmetros de Yin (2003), o presente estudo apresenta-se como um caso único, holístico e do tipo exploratório, principalmente pela natureza rara de encontrar casos de aplicação do Método Híbrido CONWIP/KANBAN no mercado.

Como é coerente na metodologia de estudo de caso, não tem sentido estabelecer hipóteses formais a priori. Entretanto, conforme Yin (2003), é satisfatório o estabelecimento de proposições como respostas às questões do estudo já apresentadas na introdução. Este procedimento auxilia o pesquisador a direcionar o trabalho de coleta de informações.

- Proposição 1: A escolha do método de controle da produção está diretamente relacionada às características encontradas em cada processo produtivo, como, por exemplo, tamanho do lote, grau de previsibilidade da demanda, nível de repetição, diversificação (variedade de produtos diferentes) e distinção (variedade de modelos), conforme definidos em MacCarthy e Fernandes (2000) e em Fernandes e Godinho Filho (2010).

- Proposição 2: O Método Híbrido CONWIP/ $K A N B A N$ é o que melhor se adequa em ambientes produtivos com alto índice de customização de produtos, mix variável de produtos, demandas incertas e não previsíveis.

- Proposição 3: Os resultados alcançados com o Método Híbrido CONWIP/KANBAN são superiores aos resultados obtidos por métodos de KANBAN e CONWIP em ambientes de produção de pequenos lotes de produtos customizados.

\subsection{Limitações do estudo de caso}

Os problemas relacionados com a validade e a confiabilidade dos resultados da investigação não são, de forma alguma, exclusivos do método estudo de caso. Se neste tipo de pesquisa o problema está na dependência do julgamento do investigador, que carrega sempre uma certa carga de subjetividade, no método de simulação, por exemplo, os problemas estão associados a certo grau de artificialidade das situações que o próprio método implica.

Um dos problemas mais comumente relacionados ao estudo de caso é a sua validade externa, pois é impossível proceder a generalizações a partir do estudo de um só caso. O objetivo deste estudo não foi fazer generalizações estatísticas de resultados, mas somente generalizações analíticas.

Segundo Ghiglione e Matalon (1992), a validade e a confiabilidade de um estudo estão também muito dependentes das técnicas de coleta e de tratamento dos dados utilizados e da adequação entre estas e os objetivos desse mesmo estudo. Se essas técnicas forem selecionadas e aplicadas corretamente, com os procedimentos devidamente explicitados, os problemas serão reduzidos.

\subsection{Unidade de análise}

A unidade de análise para o presente estudo de caso foi uma empresa multinacional do setor de automação industrial que adota o Método Híbrido CONWIP/KANBAN. O nível de análise considerado foi a opinião de seus tomadores de decisão: executivos, diretores e/ou gerentes.

\subsection{Seleção do caso}

Foi selecionada uma empresa com uma característica bem peculiar, produção de pequenos lotes com alta customização. O objetivo desta análise foi entender o processo de implementação dos métodos de controle da produção (KANBAN, CONWIP, Método Híbrido CONWIP/KANBAN), analisando as necessidades geradoras, destacando problemas enfrentados e, por fim, os resultados obtidos com a implementação de seus SCO.

\subsection{Protocolo de coleta de dados}

Vários autores (EISENHARDT, 1989; YIN, 2003) argumentam que a coleta de dados qualitativos deve ser baseada em múltiplas fontes de evidência, mas sempre convergindo ao mesmo conjunto de fatos e descobertas. Dados qualitativos são considerados evidências da ligação entre dados e proposições. O presente estudo de caso foi realizado envolvendo entrevistas em profundidade com o profissional da empresa, conforme mostra a Tabela 2. Foram realizadas duas 
Tabela 2. Lista de entrevistados.

\begin{tabular}{cc}
\hline Departamento & Função \\
\hline Administrativo & Gerente operacional \\
\hline Fon
\end{tabular}

Fonte: Os autores.

reuniões, em encontros de aproximadamente 3 horas de duração, com o líder do processo de implementação dos métodos de controle da produção na empresa.

\subsection{Entrevistado}

A principal fonte de dados foi a entrevista realizada com o Gerente Operacional da unidade da empresa no Brasil. Foram obtidas informações de registros, indicadores de desempenho operacionais e gerenciais, posicionamento de mercado, entre outros.

Yin (2003) alerta aos pesquisadores que é importante, antes de iniciar quaisquer trabalhos de campo, ter uma estratégia analítica para a coleta das evidências de um estudo de caso. A estrutura de análise dos casos da pesquisa foi a seguinte: primeiramente, realizar uma narrativa simples do caso em questão; em seguida, dedicar uma seção para mostrar os resultados históricos e posteriores à implementação do método. Foi estruturada uma matriz de variáveis importantes durante a condução das entrevistas do executivo e profissional da empresa.

\section{Resultado}

O caso estudado foi uma empresa subsidiária de um grupo americano, fabricante de produtos eletromecânicos de alta tecnologia, incluindo soluções inovadoras para o comando e monitoramento de válvulas. A empresa estudada é uma companhia global com produção, vendas e facilidades de serviço no Brasil, Estados Unidos e Reino Unido.

Sua história no Brasil até o ano de 1990 era apenas de representação da marca para o mercado local. Sua operação iniciou-se em 1991, como uma filial numa cidade do Estado de São Paulo, atuando única e exclusivamente como importadora e, a partir de 1997, iniciou-se a montagem local de conjuntos CKD (Completely Knock-Down) importados das outras unidades mundiais.

Em 2002, iniciou-se a nacionalização dos produtos para o mercado brasileiro, atuando de forma completa, desde o desenvolvimento até a manufatura.

No final de 2007, a empresa possuía 80 funcionários divididos nas seguintes áreas: cinco funcionários na gerência, 15 em vendas, 28 no administrativo e 32 na operação, trabalhando com quatro linhas de produção divididas em quatro células cada, e com faturamento local de aproximadamente dez milhões de dólares por ano. A empresa trabalhava com os seguintes tipos de produção: MTS - Make to Stock (produzido para estoque) e MTO - Make to Order (produzido sobre pedido).

\subsection{Período estudado}

O enfoque desse estudo são os acontecimentos dos anos de 2002 a 2007, quando ocorreu uma série de mudanças na empresa, as quais se pretende demonstrar por meio da análise dos resultados de três principais anos desse período, a saber: 2005, 2006 e 2007.

\subsection{Situação problema}

No ano de 2002, quando a empresa iniciou a nacionalização de produtos e processos, foi verificado um crescente aumento dos produtos e, consequentemente, aumento da produção. Como resultado, o mix de produtos aumentou e as demandas tornaram-se ainda mais variadas e sem nenhuma possibilidade de previsão.

No ano de 2004, a empresa comercializou um total de 39.500 produtos, equivalente a 63 famílias distintas. Os gráficos das Figuras 5 e 6 indicam um pareto das famílias por demanda, no período referenciado. No eixo das abscissas, tem-se o número de famílias comercializadas e as quantidades de itens por família são indicadas no eixo das coordenadas.

Para ilustrar melhor a quantidade de variações possíveis, o gráfico da Figura 6 foi plotado em uma escala logarítmica:

As famílias foram subdivididas em três grupos principais: A, B e C.

- Grupo A - coluna rachuradas : famílias com demandas maiores que 180 peças mensais. Este grupo representa $6 \%$ das variações, $64 \%$ dos itens produzidos; contudo, apenas $10 \%$ da receita de vendas.

- Grupo B - colunas sem preenchimento: famílias com demandas menores que 180 peças e maiores que 12 peças mensais. Este grupo representa $16 \%$ das variações, $29 \%$ dos itens produzidos e corresponde a $56 \%$ da receita de vendas.

- Grupo C - colunas preenchidas com pontos: famílias com demandas menores que 12 peças mensais. Este grupo representa o maior percentual de variações, totalizando $78 \%$, com somente $7,5 \%$ dos itens produzidos e um total de $34 \%$ da receita de vendas.

Na Figura 7, pode-se verificar melhor qual é a relação das três informações em cada um dos grupos: quantidade de itens fornecidos, faturamento e quantidade de famílias distintas.

Pode-se verificar que os três grupos de produtos evidenciados têm sua importância, seja para ocupação da capacidade de produção, com os altos volumes (Grupo A), seja pela representação financeira expressiva na receita de vendas (Grupo B) ou ainda 


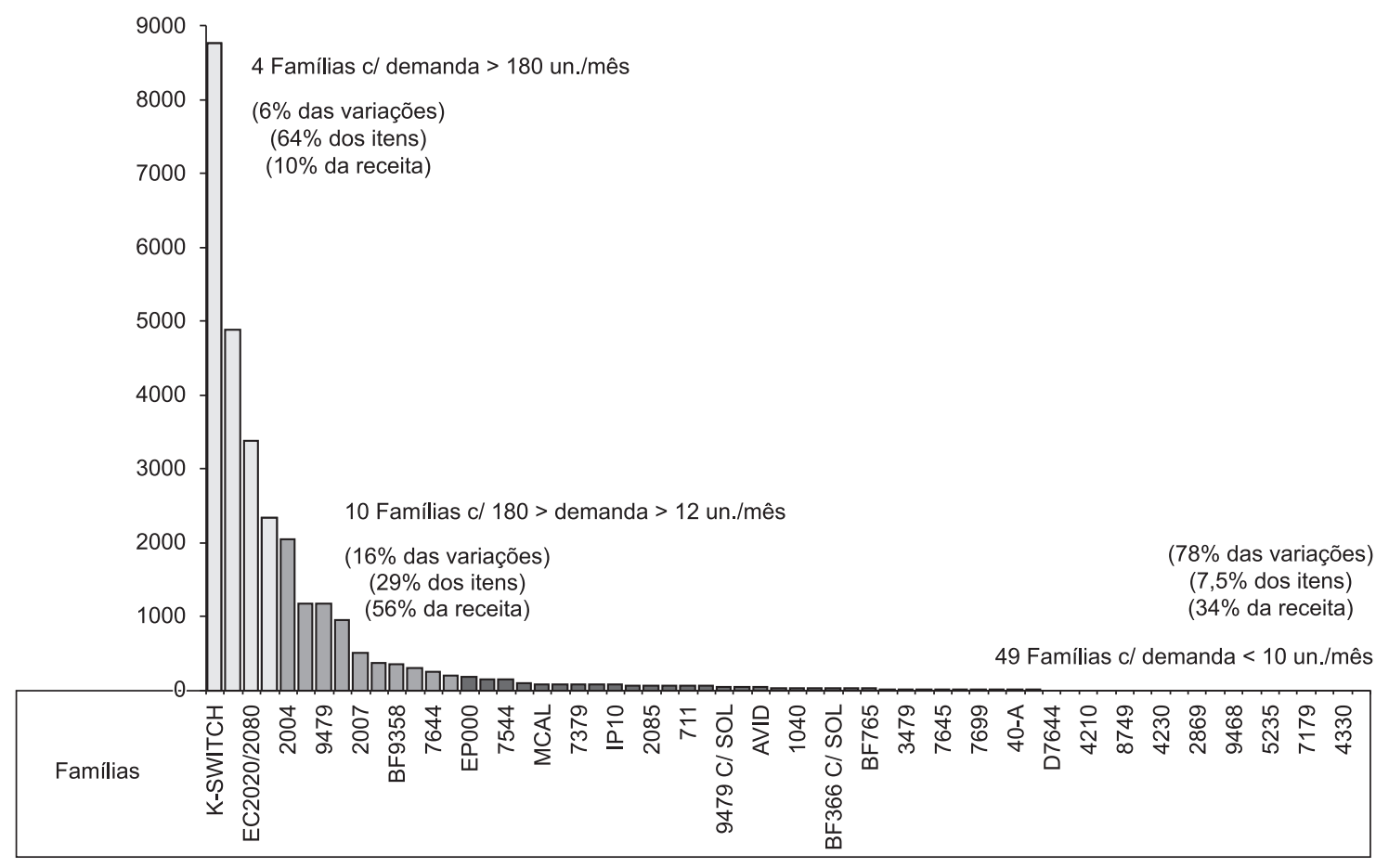

Figura 5. Pareto das famílias por demanda - dados de referência: jan/4 a dez/4. Fonte: A empresa.

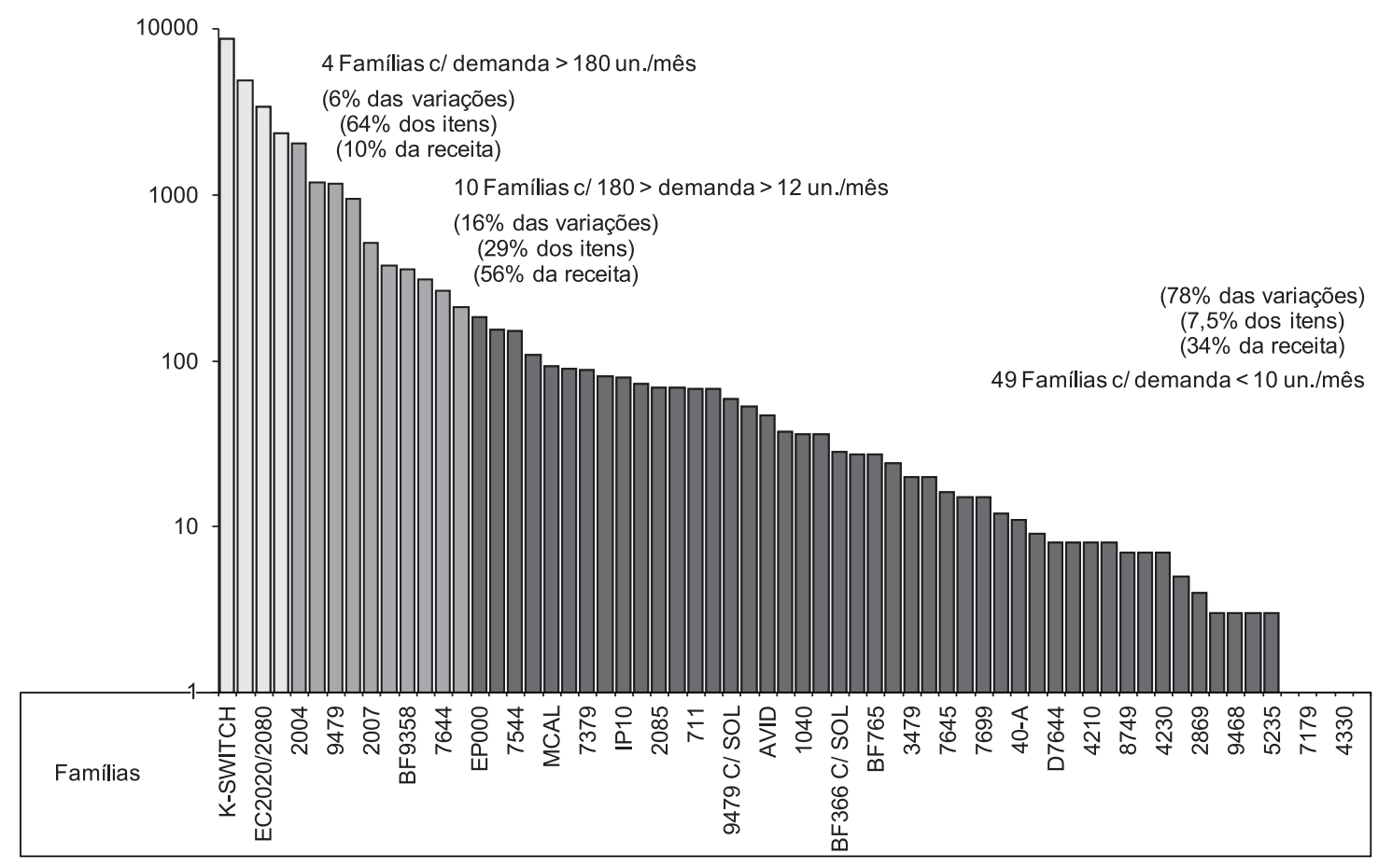

Figura 6. Pareto das famílias por demanda logarítmica - dados de referência: jan/4 a dez/4. Fonte: A empresa.

para o atendimento às necessidades do mercado, por meio da quantidade de famílias (Grupo C).

Para ilustrar a variação e a falta de previsibilidade de demanda intrínseca a este tipo de mercado e inerente à família de produtos em questão, a Figura 8 faz referência ao comportamento de três dessas famílias pertencentes aos grupos A, B e C, durante o período de aproximadamente três anos.

A partir da análise do gráfico da Figura 8, verifica-se que não existe nenhuma sazonalidade regular nos 


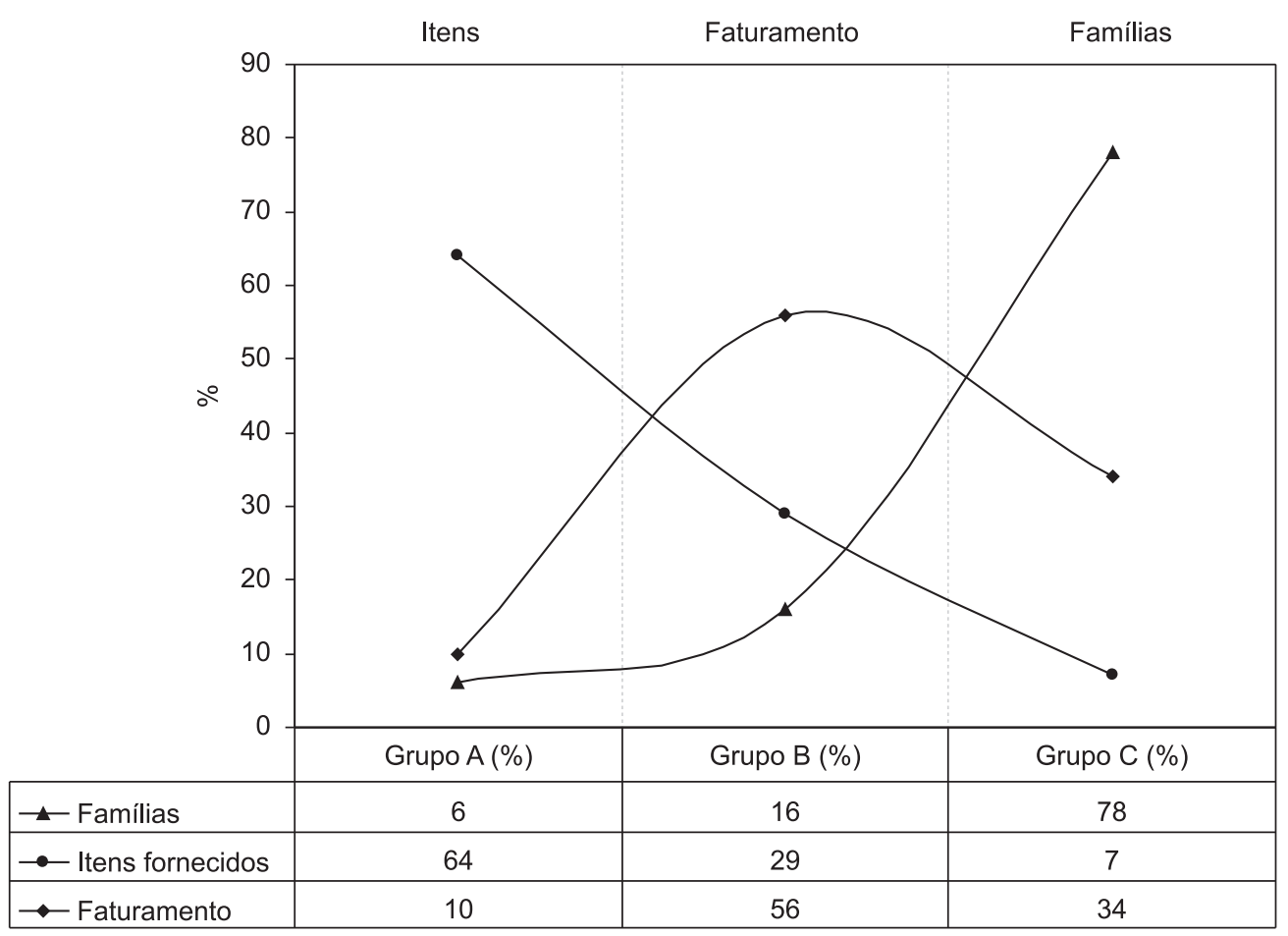

Figura 7. Paretos que se contrapõem - Grupos ABC. Fonte: A empresa.



Figura 8. Demanda de produtos acabados Grupo A, B e C. Fonte: A empresa.

volumes consumidos, o que impede programar a produção com base em previsão de demanda, uma vez que a demanda é imprevisível.

O problema da empresa nesse cenário era como programar a produção, levando em consideração esse mix variável de produtos e a baixa previsibilidade de vendas. Em busca de resolver esse problema, os gerentes da empresa implantaram uma série de processos/metodologias, que serão abordados a partir de agora. 


\subsection{Processos e implantação}

Como consequência da nacionalização de produtos e processos e do aumento do volume, surge a necessidade de adaptar o processo produtivo a algum método de controle de produção.

Seguindo as diretrizes da matriz, a empresa decidiu implantar o controle de produção por meio do MRP - Manufacturing Resource Planning (Planejamento das Necessidades de Manufatura), programando a produção com análise de previsão da demanda baseada em histórico.

Esse processo teve um tempo de maturação de quase dois anos para ser implantado, prevalecendo até o ano de 2004.

Como resultado dessa adaptação, a linha de produção foi caracterizada conforme ilustrado na Figura 9.

Alimentado pelo MPS (plano mestre de produção), o MRP programa a produção por meio de cálculos de previsão de demanda (PR), baseados em histórico; e estabelece níveis de estoque mínimo e máximo de cada produto nos estoques de: almoxarifado (AL), estoques intermediários (EI) e produto acabado (PA).

Ao atingir os níveis mínimos de estoque de produto acabado (PA) estabelecidos no MRP, as ordens de compra (OC) e de produção (OP) são automaticamente disparadas aos fornecedores (FN) e programadas para a produção (PRD), respectivamente.

Como é a previsão da demanda média estatística de produto acabado (PR) que realimenta o início do processo, e não a demanda efetiva, isto equivale ao conceito de sistema push (empurrado). A tendência é que o almoxarifado (AL) e os estoques intermediários (EI) mantenham-se elevados, mesmo por períodos sem demanda.

O MRP não correspondia de maneira eficiente às necessidades da empresa no que se referia a três particularidades do cenário:

- O mix variável de produtos tende a provocar elevação nos níveis de estoque (estocagem em todos os níveis);
- O conceito MRP é complexo e depende de informações estatísticas confiáveis não existentes, ocasionando uma programação equivocada da produção;

- A falta de previsibilidade de demanda somada à programação equivocada fazia com que as necessidades dos clientes (pequenos lotes e customização) não fossem atendidas, gerando altos prazos de entrega e baixo nível de serviço.

Por outro lado, as operações possíveis de serem realizadas são feitas e adiantadas o quanto possível.

Com os resultados ineficientes obtidos pelo MRP, surge uma nova diretriz da matriz para controlar a produção por meio do KANBAN. Essa nova metodologia foi implantada no início de 2005, concebendo sua linha de produção conforme ilustração na Figura 10.

Para adaptação da produção com o método de controle $K A N B A N$, foram calculados quais eram os lotes ótimos de produção de cada peça, isto é, o número de cartões KANBAN (KB), assim como os níveis de estoque em cada etapa da produção: loja (LJ), supermercado (SM), linha (LN) e produto acabado (PA).

Quando o estoque de produto acabado (PA) alcança o nível mínimo pré-determinado ou há pedido de venda (PV), o cartão KANBAN (KB) é transferido para a linha (LN), que é o estoque imediatamente anterior a ele. Esse processo se repete sucessivamente entre os estágios anteriores, supermercado (SM) e loja (LJ) até que os saldos sejam suficientes para atender à demanda.

Isto equivale ao conceito de sistema pull (puxado), pois o processo de abastecimento só ocorre em resposta a uma demanda, e a tendência é que os estoques mantenham sempre metade da demanda estocada, mesmo sem demanda. Na parada de um processo, o estoque do processo posterior permite que ele e os posteriores prossigam, ao menos até que o conteúdo daquele buffer se acabe.

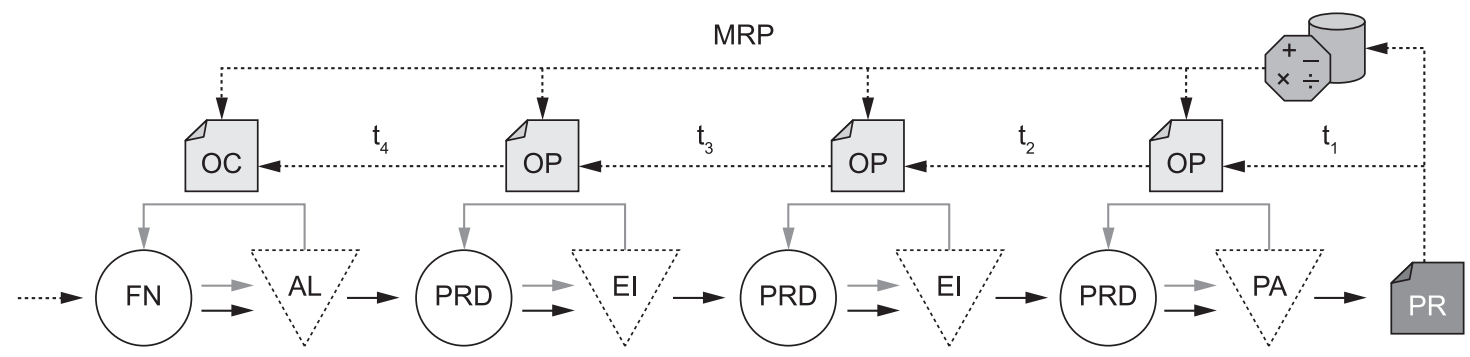

PR: Pressão OP: Ordem de Produção OC: Ordem de Compra FN: Fornecedor AL: Almoxarifado PRD: Produção El: Estoque Intermediário PA: Produto Acabado t: Tempo

Figura 9. Controle de produção MRP. Fonte: A empresa. 


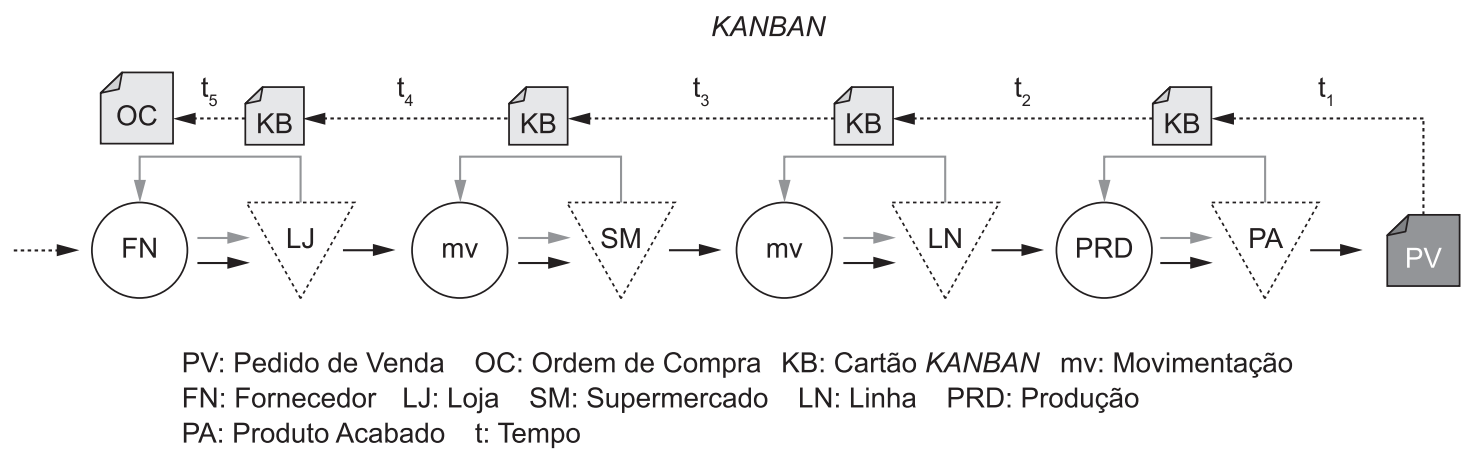

Figura 10. Controle de produção KANBAN. Fonte: A empresa.

Ainda assim, a implementação do KANBAN também não correspondia de maneira eficiente às necessidades da empresa estudada, no que se refere às três particularidades:

- O mix variável de produtos tende a provocar elevação nos níveis de estoque na loja (LJ), no supermercado (SM) e na linha (LN);

- As demandas variadas impedem que as informações cheguem rapidamente ao início da cadeia, atrasando a liberação das ordens de compra (OC) e consequentemente o não atendimento dos prazos de entrega estabelecidos;

- Os processos de movimentação são realizados pelos mesmos operadores de produção e o efeito de estoque fica neutralizado, pois eles têm que parar a produção para a movimentação acontecer, prejudicando a eficiência desse método e perdendo a essência do KANBAN.

Em busca de um método que traduzisse a realidade da empresa, foi implantado o controle de produção por meio do CONWIP, passando, então, a partir do início de 2006, a conceber sua linha de produção conforme ilustrado na Figura 11.

O método de controle CONWIP pode ser considerado como um KANBAN de um único estágio. Os níveis de estoques intermediários em repouso são nulos e são estabelecidos apenas os níveis de estoque para o produto acabado (PA).

Quando o nível de estoque de produto acabado (PA) atinge seu nível mínimo e existe pedido de venda (PV), uma ordem de produção (OP) é gerada para o primeiro estágio, fazendo com que as peças sejam empurradas o mais rápido possível através do sistema.

Isto equivale ao conceito de sistema pull (puxado), pois o processo de abastecimento só ocorre em resposta a uma demanda. Os buffers loja (LJ), supermercado (SM) e linha (LN) esgotam-se, pois eles estão dimensionados de acordo com o lote do pedido de venda (PV). As operações possíveis de serem realizadas são adiantadas até que as peças comprometidas se esgotem.
Sua principal desvantagem é que há uma tendência de acúmulo de peças no estoque imediatamente anterior àquele que é o gargalo do processo ou em que o processo parou. Além disso, como o conceito foi desenhado para processos produtivos e não de abastecimento, quando aplicado aos fornecedores (FN), perde quase totalmente o sentido, uma vez que o prazo de entrega dos insumos é longo e incapaz de reagir à demanda real.

Assim sendo, o ressuprimento de fornecedores externos teve que ser tratado separadamente por meio de cálculos estatísticos de previsão de demanda, baseados em histórico e acordos com estocagem em fornecedores, devido ao seu longo prazo de entrega e múltiplas necessidades, conforme Figura 12.

Até 2006 o método de controle CONWIP foi o que melhor se adequou ao cenário da empresa estudada, mas ainda não correspondia totalmente às necessidades do mercado no que tange a algumas particularidades:

- Esse método minimiza em grande parte os níveis de estoque em linha, quando comparado ao KANBAN, mas o mix variável de produtos ainda é responsável por níveis de estoques consideráveis nos outros locais;

- A produção de lotes de baixos volumes associada ao mix variável de produtos dificulta $o$ atendimento dos prazos de entrega definidos junto com os clientes.

Dessa forma, o método CONWIP apresenta melhores resultados quando comparado ao KANBAN, porém ainda não o suficiente para atender às necessidades do mercado.

Uma particularidade muito importante foi atendida:

- O efeito de retardo causado pelas demandas variadas foi reduzido ao mínimo, pois a informação chega diretamente ao início da cadeia, empurrando a produção com mais rapidez.

Buscando em pesquisas acadêmicas a otimização da produção e um melhor desempenho do nível de serviço ao cliente, o Gerente Operacional encontrou uma pesquisa do MIT na internet, realizada por Bonvik et al. (1997). Constatou então uma similaridade 


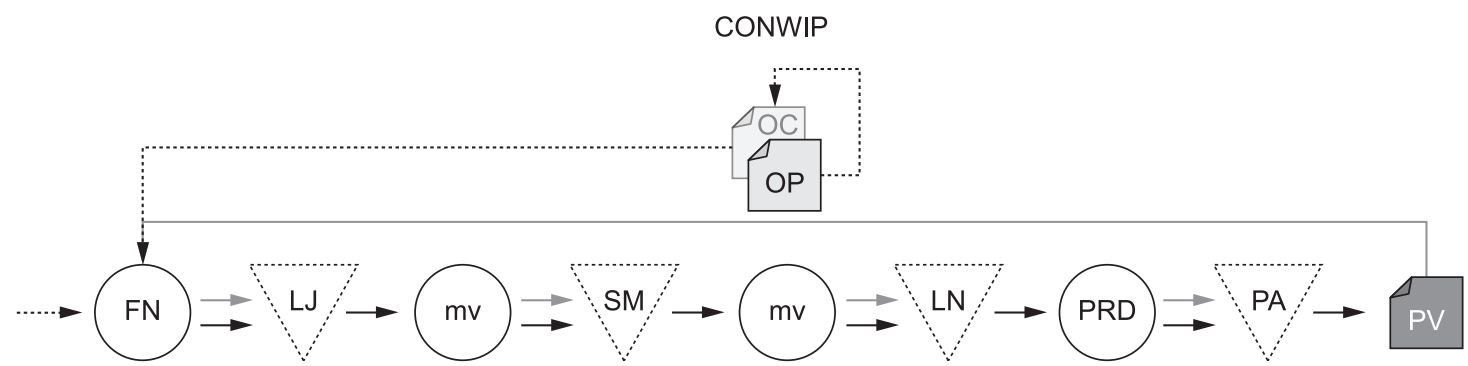

PV: Pedido de Venda OP: Ordem de Produção OC: Ordem de Compra mv: Movimentação

FN: Fornecedor LJ: Loja SM: Supermercado LN: Linha PRD: Produção PA: Produto Acabado

Figura 11. Controle de produção CONWIP. Fonte: A empresa.
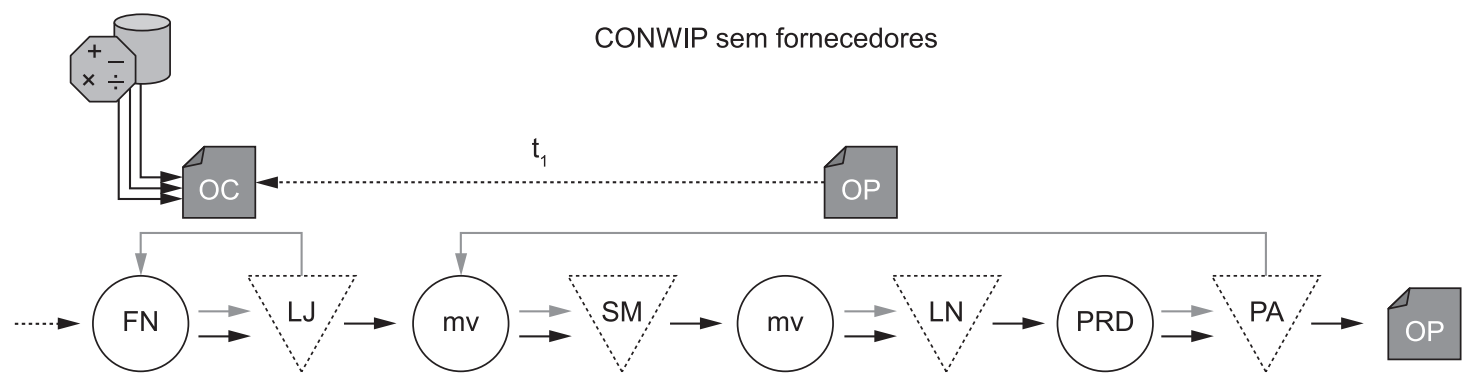

OP: Ordem de Produção OC: Ordem de Compra mv: Movimentação FN: Fornecedor LJ: Loja SM: Supermercado LN: Linha PRD: Produção PA: Produto Acabado t: Tempo

Figura 12. Controle de Produção CONWIP sem fornecedores. Fonte: A empresa.

do estudo com a realidade de sua linha de produção (composta de até quatro estágios de montagem), no que tange ao mix variável de produtos e a demandas variadas e não previsíveis. Analisando as proposições e benefícios apresentados neste estudo, o gerente operacional chegou à conclusão de que a aplicação do Método Híbrido CONWIP/KANBAN para controle da produção traria melhores resultados, sendo implantado a partir do início de 2007.

Essa nova metodologia concebe o cenário ilustrado na Figura 13.

Assim como no CONWIP, o ressuprimento de fornecedores externos precisa ser tratado separadamente por MRP, devido ao seu longo prazo de entrega e a múltiplas necessidades.

Os níveis de estoques intermediários (SA) em repouso são praticamente nulos e são estabelecidos apenas os níveis de estoque para o produto acabado (PA).

Quando o estoque de produto acabado (PA) está vazio e existe pedido de venda (PV), uma ordem de produção $(\mathrm{OP})$ é gerada para o primeiro estágio CONWIP. Como é a demanda de produto acabado que alimenta o início da cadeia, isto equivale ao conceito de sistema pull (puxado).

Observou-se que grande parte dos produtos comercializados, apesar de alto nível de customização, possuía um nível padronizado até determinado estágio (subconjuntos). Com este novo método, antes da ordem de produção $(\mathrm{OP})$ ir para a produção, o sistema gerava uma lista de subconjuntos que seriam utilizados nos produtos para atendimento do pedido de venda (PV), agrupando-os e lançando-os para a produção por meio de KANBAN. Portanto, a produção de semiacabado (PRD) era controlada por KANBAN, que determinava lotes ótimos de cada subconjunto.

As peças são empurradas o mais rápido possível através do sistema, até chegarem à produção final (PRD), que utilizava o subconjunto para a customização do produto acabado (PA) para atendimento de pedido de venda (PV).

Nesse cenário, o Método Híbrido CONWIP/ $K A N B A N$ atendeu completamente às necessidades da empresa no que se refere a três particularidades:

- O mix variável de produtos tende a provocar elevação nos níveis de estoque. Por outro lado, com o aumento da taxa de produção, os produtos giravam mais rapidamente, reduzindo os níveis de estoque ainda mais que no CONWIP;

- Mesmo com o mix variável de produtos e a produção de baixo volume, os prazos de entrega foram alcançados pela agilidade que a produção (PRD) de subconjuntos no KANBAN ofereceu ao sistema, gerando melhores níveis de serviço que os alcançados anteriormente; 


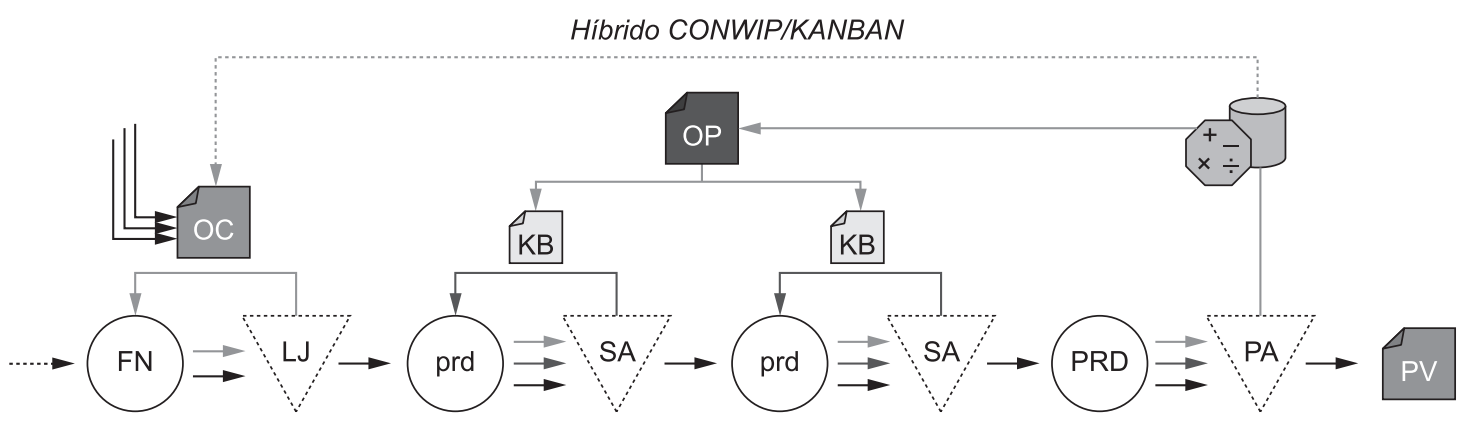

PV: Pedido de Venda KB: Cartão KANBAN OP: Ordem de Produção OC: Ordem de Compra FN: Fornecedor LJ: Loja SA: Semi-Acabado prd: Produção Semi-Acabado PRD: Produção Final PA: Produto Acabado

Figura 13. Controle de produção híbrido CONWIP/KANBAN. Fonte: A empresa.

- Assim como no CONWIP, o efeito de retardo causado pelas demandas variadas foi praticamente neutralizado, pois a informação chega diretamente ao início da cadeia, empurrando a produção com mais rapidez.

Ao longo de cada etapa da solução do problema, observou-se o comportamento do nível de estoque total (produto acabado, estoque em processo (WIP) e matéria-prima).

Preliminarmente, a conclusão dos profissionais envolvidos no projeto foi a de que à medida que o método era mais adequado ao processo, o nível de estoque diminuía. Na Figura 14 busca-se ilustrar essa constatação.

\subsection{Resultados alcançados}

Para expressar os resultados alcançados, foram considerados somente os três principais anos, período no qual foram implantados os métodos de controle de produção em estudo, conforme Tabela 3.

O primeiro resultado que será apresentado é o OTD - On Time Delivery (prazo de entrega), conforme demonstrado na Figura 15.

Conforme analisado no gráfico da Figura 15, o On Time Delivery (OTD) teve uma evolução significativa, quando comparados os diferentes anos.

No ano de 2005, com a utilização do método KANBAN, o On Time Delivery (OTD) apresentou média de $53 \%$, enquanto, em 2006, com o método CONWIP, uma média de $72 \%$ e, por fim, com a utilização do Método Híbrido CONWIP/KANBAN, houve uma elevação para $89 \%$ de atendimento. Houve melhoria de $34 \%$ entre os anos de 2005 e 2006 e de $24 \%$ entre os anos de 2006 e 2007.

Para verificar melhor esse crescimento ao longo dos períodos, a Figura 16 identifica a evolução do prazo de entrega continuamente ao longo dos três anos analisados.

Analisando o gráfico da Figura 16, verifica-se que, durante os três anos, o OTD teve taxa de crescimento de aproximadamente $30 \%$ ao ano e de 1,2 vezes no final de três anos. Isso demonstra que esta melhoria está ligada à evolução dos métodos de controle de produção da empresa.

Com a implantação do controle pelo Método Híbrido CONWIP/KANBAN em 2007, a empresa conseguiu atender, na maior parte dos meses, ao estabelecido como meta para On Time Delivery (OTD), atingindo valores nos patamares maiores que $90 \%$.

Outra melhora significativa foi o ITO - Inventory Turnover (giro de estoque), que pode ser verificado na Figura 17.

$\mathrm{O}$ giro de estoque teve seu pior resultado durante o período que a produção foi controlada pelo MRP (2002-2004), atingindo um giro médio de apenas 1,8 vezes por ano, consequência do alto nível de estoque necessário para atendê-lo.

Com o amadurecimento do MRP, ao final de sua utilização o Inventory Turnover (ITO) chegou a atingir um giro de 2,6 vezes por ano.

Nos três anos seguintes, com a implantação do KANBAN, CONWIP e Método Híbrido CONWIP/ KANBAN, o Inventory Turnover (ITO) aumentou de 3,2 , para 3,4 e 3,6 vezes por ano.

Outros principais ganhos da empresa, cujos dados não estão ilustrados em figuras específicas, foram: elevação da produtividade em $40 \%$ sem o aumento de headcount, quando comparados os anos de $2005 \mathrm{e}$ 2007; crescimento de $18 \%$ no faturamento do mesmo período e redução de Slow Move Itens (itens com baixa movimentação) em mais de $70 \%$, devido à alta racionalização dos estoques, que foram reduzidos em até $20 \%$ do seu valor e quase $50 \%$ na sua área.

Durante a entrevista realizada com o Gerente Operacional, foram coletados e classificados fatores relacionados à implantação do Método Híbrido CONWIP/KANBAN, conforme Figura 18.

Observando os resultados obtidos na Figura 18, verifica-se que o apoio da direção, a escolha de um time multifuncional, o envolvimento do usuário, a escolha de um líder para o projeto e a cultura da 
Tabela 3. Período $\times$ Controle de produção.

\begin{tabular}{cc}
\hline Ano & Método para controle de produção \\
\hline 2005 & $K A N B A N$ \\
2006 & $C O N W I P$ \\
2007 & Híbrido CONWIP/KANBAN \\
\hline
\end{tabular}

Fonte: Os autores. organização foram fatores decisivos para o alcance do sucesso na implantação do Método Híbrido CONWIP/KANBAN.

Não houve o envolvimento de nenhum consultor externo durante o desenvolvimento do projeto, já que o método em questão era pouco explorado e desconhecido, principalmente aqui no Brasil.



Figura 14. Controle de produção híbrido CONWIP/KANBAN. Fonte: A empresa.



Figura 15. On Time Delivery - Anual out/2005 a set/2007. Fonte: A empresa. 
Um ponto importante a ser destacado é a inexistência de uma metodologia definida para implantação do Método, o que reforça a perspicácia do líder do projeto e sua capacidade de envolvimento e mobilização do time.

Conforme observado, certamente, o suporte dos fornecedores foi fator preponderante para a compreensão do problema e a participação intensa em sua solução.

Uma análise sintética da Figura 19 dos resultados obtidos dessa implantação pode ser feita ao analisar alguns parâmetros desenvolvidos ao longo deste trabalho. Dentre eles, destacam-se redução expressiva dos erros de previsão, isto é, programação da produção

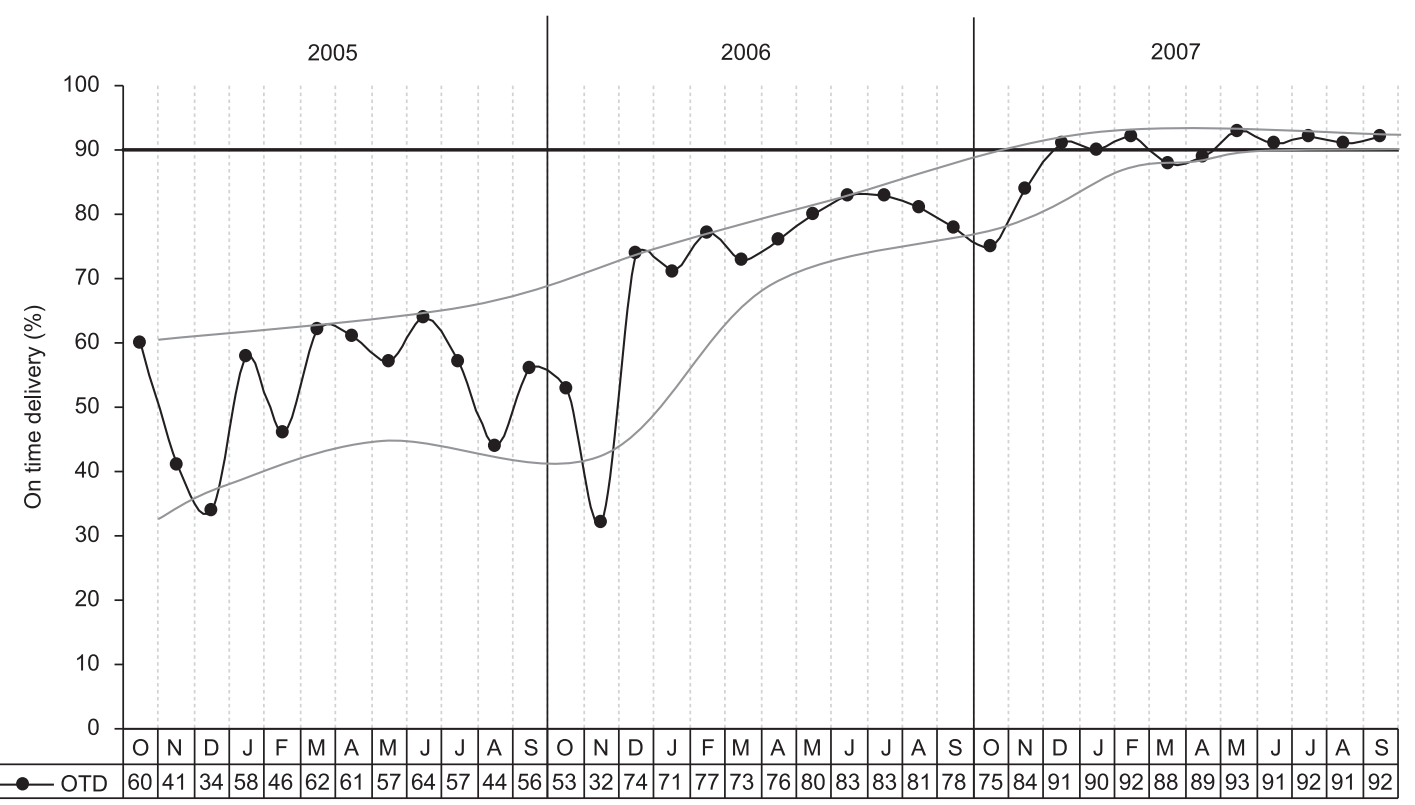

Figura 16. On Time Delivery - Linear out/2005 a set/2007. Fonte: A empresa.

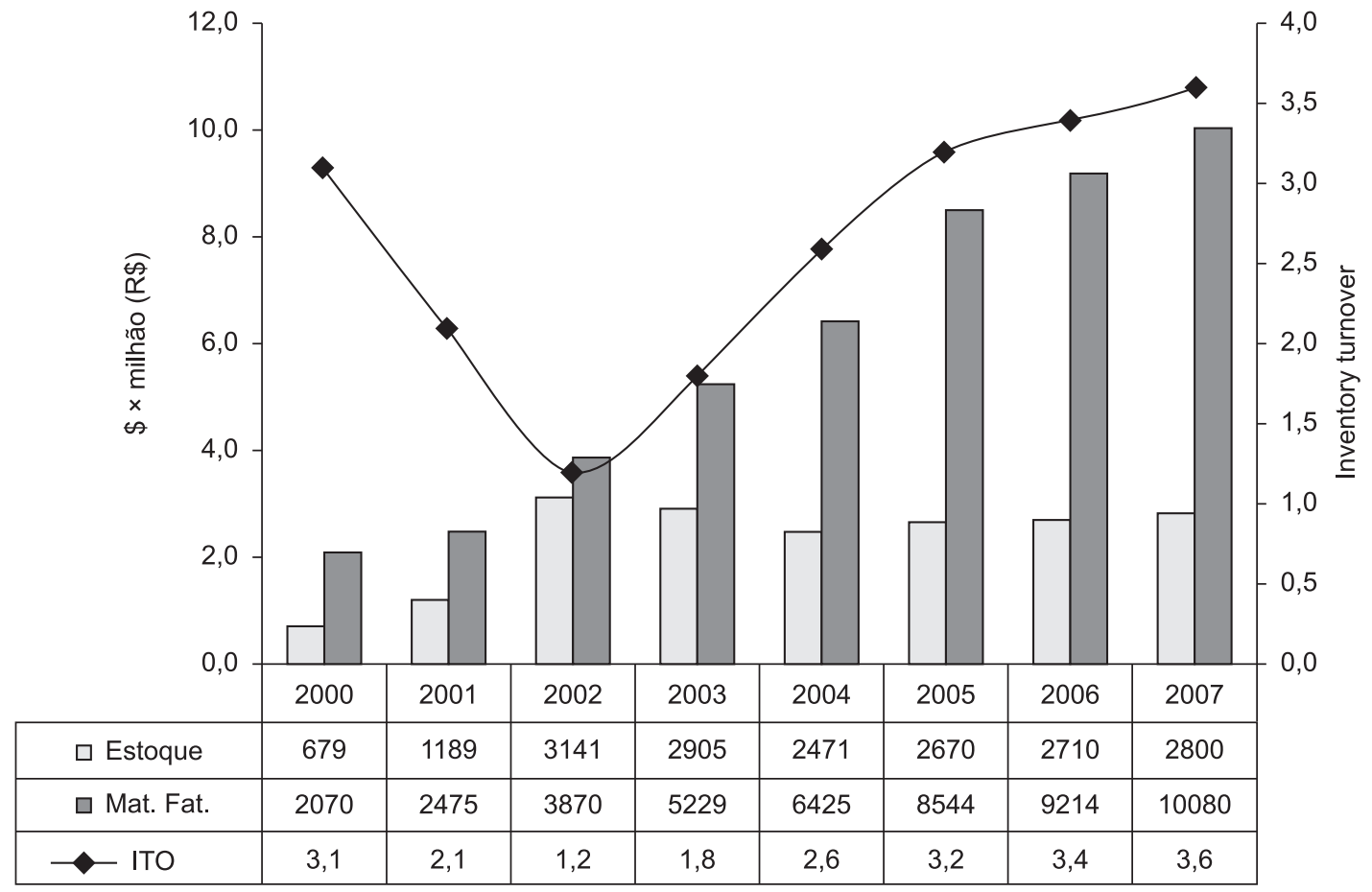

Figura 17. Evolução - Inventory Turnover. Fonte: A empresa. 
Fatores que afetam o método híbrido CONWIP/KANBAN

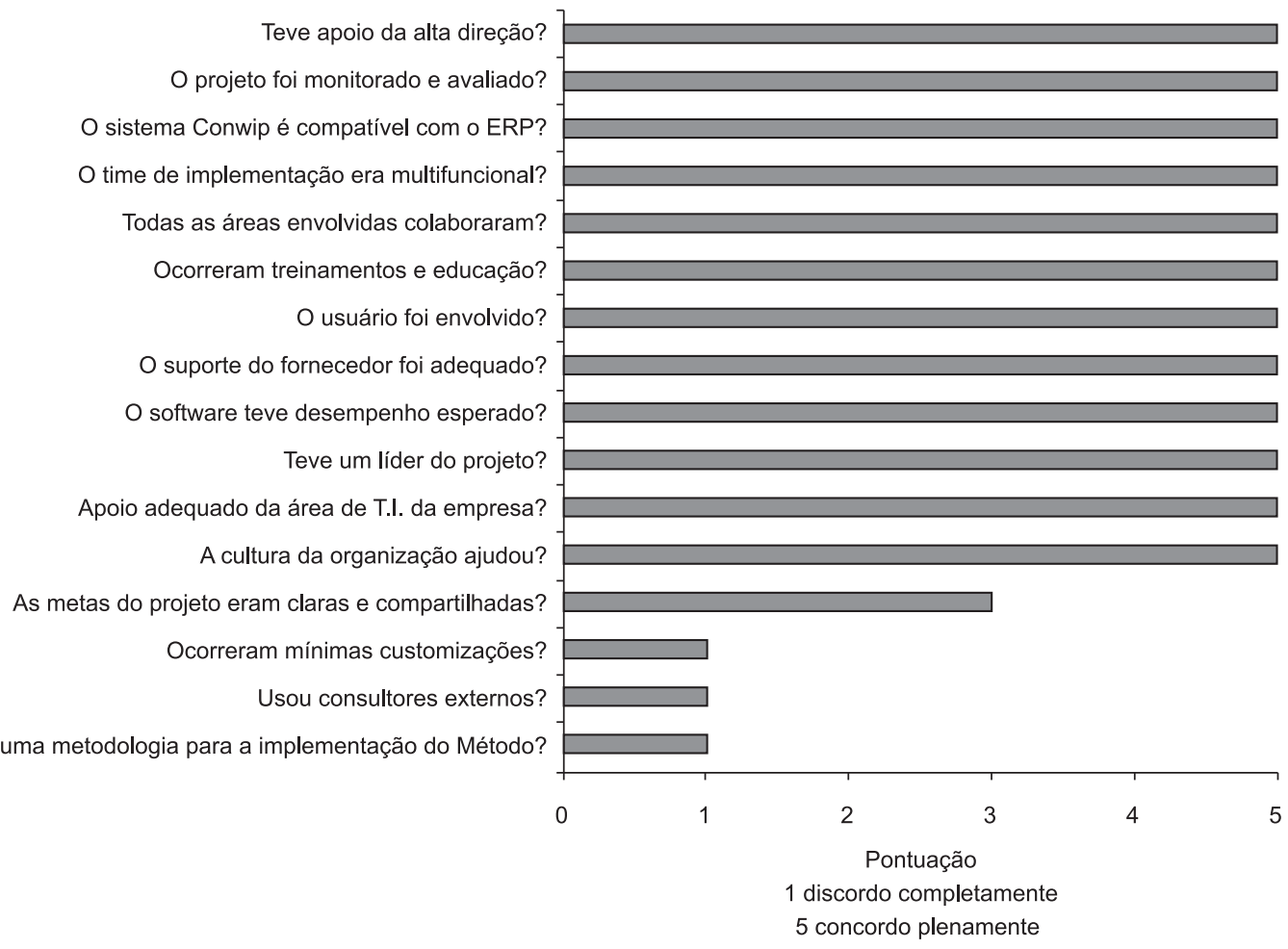

Figura 18. Resultados obtidos com a implantação do Método Híbrido CONWIP/KANBAN. Fonte: Os autores.

Resultados obtidos com a implantação do método híbrido CONWIP/KANBAN

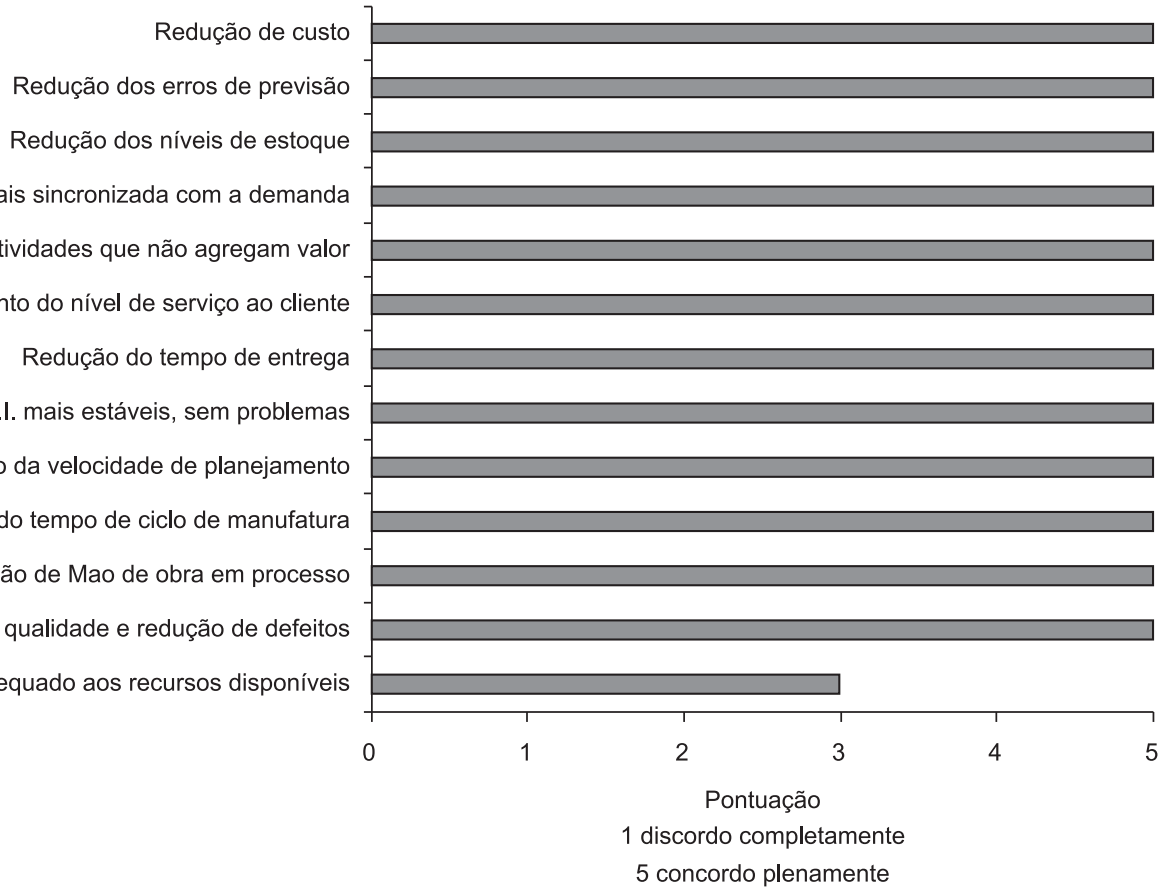

Figura 19. Fatores que afetam o Método Híbrido CONWIP/KANBAN. Fonte: Os autores. 
Tabela 4. Característica operacional $\times$ SCO.

\begin{tabular}{|c|c|c|c|c|}
\hline \multirow{2}{*}{\multicolumn{2}{|c|}{ Característica operacional }} & \multicolumn{3}{|c|}{ SCO } \\
\hline & & KANBAN & CONWIP & HÍBRIDO CONWIP/KANBAN \\
\hline \multicolumn{2}{|c|}{ Volume de produção } & Médio & Baixo & Baixo \\
\hline \multicolumn{2}{|c|}{ Grau de previsibilidade da demanda } & Elevado & Baixo & Baixo \\
\hline \multicolumn{2}{|l|}{ Tamanho do lote } & Médio & Baixo & Baixo \\
\hline \multirow[t]{2}{*}{ Mix de produtos } & Diversificação & Baixo & Elevado & Elevado \\
\hline & Distinção & Baixo & Elevado & Elevado \\
\hline \multicolumn{2}{|l|}{ Nível de repetição } & Elevado & Baixo & Moderado \\
\hline \multicolumn{2}{|c|}{ Prazo de entrega do fornecedor } & Just in Time & Baixo & Elevado \\
\hline
\end{tabular}

Fonte: Os autores.

adequada à demanda, diminuição dos níveis de estoque, melhoria nos prazos de entrega, corte de mão de obra em processo e, principalmente, dois pontos importantes: aumento do nível de serviço ao cliente e melhoria da qualidade e redução de defeitos nos produtos por montagem incorreta ou troca de componentes na produção.

\subsection{Conclusão}

Este trabalho teve o objetivo de entender, descrever e investigar os sistemas de coordenação de ordens KANBAN, CONWIP e Método Híbrido CONWIP/ $K A N B A N$, implementados em um ambiente real de produção, procurando identificar seus resultados e as principais dificuldades encontradas. Conforme Lage Junior e Godinho Filho (2008, p. 186),

[...] o estudo de aplicação na prática de adaptações de sistemas KANBANs somente desenvolvidas de forma teórica é um tema com muitas oportunidades de exploração.

Esse foi o foco deste trabalho.

$\mathrm{O}$ estudo investigou os $\mathrm{SCO}$ implementados em uma empresa fabricante de produtos eletromecânicos de alta tecnologia, incluindo soluções inovadoras para o comando e monitoramento de válvulas. Seus executivos de operações tentaram diversos métodos de SCO durante o período de 2005 a 2007, desde MRP, passando por KANBAN e CONWIP até chegar ao Método Híbrido CONWIP/KANBAN (conforme proposto por Bonvik et al., 1997) visando atingir suas metas de atendimento da demanda ao menor custo possível.

O aprendizado teórico e prático permitiu aos executivos da empresa compreender seus processos e atingir resultados cada vez mais positivos. Seu sistema produtivo de pequenos lotes com alta customização e demanda incerta ficou mais eficiente com a implementação do sistema Híbrido CONWIP/ KANBAN, conforme mostra o resumo de principais indicadores da empresa na Tabela 4.
Tabela 5. Resultados Obtidos $\times$ SCO.

\begin{tabular}{cccc}
\hline Resultados & KANBAN & CONWIP & $\begin{array}{c}\text { HÍBRIDO } \\
\text { CONWIP/ } \\
\text { KANBAN }\end{array}$ \\
\hline $\begin{array}{l}\text { Nível de } \\
\text { serviço } \\
\begin{array}{l}\text { Nível dos } \\
\text { estoques }\end{array}\end{array}$ & Baixo & Moderado & Alto \\
\hline Fonte: Os autores. & & Moderado & Baixo \\
\hline
\end{tabular}

Estes resultados indicam que o desempenho da operação com o SCO Híbrido CONWIP/KANBAN, na prática, foi superior aos sistemas puros testados. Desta forma, pode-se afirmar que a busca por sistemas híbridos é um objetivo desta empresa, principalmente em função do aumento da variedade de produtos exigidos pelo mercado, acompanhado pela redução dos volumes solicitados, visto que isso exige maior flexibilidade e rapidez do sistema produtivo.

Além do relato dos resultados encontrados, foram investigadas algumas questões de pesquisas acadêmicas, que cabe agora serem respondidas:

1) Quais variáveis têm impacto na seleção do SCO visando ao máximo nível de serviço ao menor custo possível?

As características peculiares desta empresa indicam que as variáveis operacionais: volume de produção (alto ou baixo), grau de previsibilidade da demanda (alto ou baixo), tamanho dos lotes de produção (alto ou baixo), nível de repetição, diversificação do mix de produção em termos de famílias de produto, distinção de cada família em termos de variedade de modelos são relevantes e influenciam a tomada de decisão de seleção do SCO.

2) Quando o Método Híbrido CONWIP/KANBAN é mais adequado nos sistemas produtivos?

A Tabela 5 mostra um resumo das características consideradas importantes pelos executivos da empresa pesquisada.

O Método Híbrido CONWIP/KANBAN é mais eficiente para sistemas produtivos dedicados à produção de pequenos lotes e alto nível de customização. 


\section{3) Quais os resultados obtidos com a aplicação} do Método Híbrido CONWIP/KANBAN numa empresa de produtos customizados, pequenos lotes e demanda incerta?

A Tabela 6 mostra os resultados obtidos a partir da escolha do método SCO na empresa pesquisada.

As lições apreendidas no caso estudado são de muita valia, principalmente por tratar-se de uma empresa brasileira que está apresentando resultados positivos e concretos com a adoção do Método Híbrido CONWIP/KANBAN. Os depoimentos do executivo revelou que o Método Híbrido CONWIP/KANBAN não é um SCO para todo tipo de organização; existe uma série de condições ambientais, mercadológicas e pré-requisitos operacionais, cuja presença é obrigatória para viabilizar sua adoção. A questão não é querer implementar o Método Híbrido CONWIP/KANBAN, mas sim poder. A organização precisa ter condições mínimas de estrutura, infraestrutura e relacionamento interorganizacional para sua implementação. Outro ponto importante que surgiu foi o aspecto cultural envolvido na implementação. A eficiência do sistema não depende só das condições técnicas operacionais existentes, mas também da transformação das relações entre setores da empresa e entre empresas. Nesse contexto, é importante quebrar as barreiras organizacionais que normalmente impedem o estabelecimento de relacionamentos colaborativos. Conforme afirma Fisher (1997), o projeto de um processo responsivo não é uma tarefa simples; entretanto, a recompensa - uma vantagem competitiva notável - pode fazer tais esforços valerem a pena.

É importante citar algumas limitações da pesquisa. A primeira é a impossibilidade de generalização estatística dos resultados, devido à utilização do método de estudo de caso único. Em segundo lugar, a pesquisa avaliou os resultados alcançados com diversos SCO; porém tem a desvantagem de estudar apenas um caso de cada categoria.

\subsection{Pesquisas futuras}

Alguns pontos merecem estudos futuros.

- Pesquisa em diferentes setores, como o eletroeletrônico, representa uma contribuição para a avaliação do processo de difusão das práticas do Método Híbrido CONWIP/KANBAN no mercado brasileiro;

- Muitos autores têm estudado o impacto da programação puxada em uma empresa; porém poucos se dedicaram a investigar o impacto sobre os membros a montante e a jusante da cadeia de suprimento. Um estudo relevante seria investigar este tema;
- Reproduções mais focadas deste estudo em Método Híbrido CONWIP/KANBAN podem trazer contribuições adicionais.

\section{Referências}

BARCO, C. F.; VILLELA, F. B. Análise dos sistemas de programação e controle da produção. A integração das cadeias produtivas com a abordagem da manufatura sustentável. In: ENCONTRO NACIONAL DE ENGENHARIA DE PRODUÇÃO, 28., 2008, Rio de Janeiro. Anais... Rio de Janeiro: ABEPRO, 2008. p. 1-7. BONVIK, A. M.; COUCH, C. E.; GERSHWIN, S. B. A comparison of Production-Line Control Mechanisms. International Journal of Production Research, v. 35, n. 3, p. 789-804, 1997. http://dx.doi. org/10.1080/002075497195713

BOONLERTVANICH, K. Extended CONWIP KANBAN System - Control and Performance Analysis. Georgia Institute of Technology, 2005.

EISENHARDT, K. M. Building theories from case study researches. Academy of Management Review, v. 14, n. 4, p. 532-550, 1989.

ELLRAM, L. M. The use of the case study method in logistics research. Journal of Business Logistics, v. 17, n. 2, p. 93-138, 1996.

FERNANDES, F. C. F.; GODINHO FILHO, M. Sistemas de coordenação de ordens: revisão, classificação, funcionamento e aplicabilidade. Revista Gestão \& Produção, v. 14, n. 2, 2007.

FERNANDES, F. C. F.; Godinho FILHO, M. Planejamento e Controle da Produção. São Paulo: Editora Atlas S.A., 2010.

FISHER, M. L. What is the right supply chain for your product? Harvard Business Review, v. 75, n. 2, p. 105-116, 1997.

GAURY E. G. A. Designing Pull Production Control Systems: Customization and Robustness. Thesis (PhD)Tilburg University, Tilburg, 2000.

GAURY, E. G. A.; PIERREVAL, H.; KLEIJNEN, J. P. C. An Evolutionary Approach to Select a Pull System among KANBAN, CONWIP and Hybrid. Journal of Intelligent Manufacturing, v. 11, n. 2, p. 157-167, 2000. http://dx.doi.org/10.1023/A:1008938816257

GERAGHTY, J.; HEAVEY, C. A review and comparison of hybrid and pull-type production control strategies. OR Spectrum, v. 27, n. 2, p. 435-457, 2005. http:// dx.doi.org/10.1007/s00291-005-0204-z

GHIGLIONE, R.; MATALON, B. O Inquérito - Teoria e prática. Oeiras: Celta, 1992. p. 55-57.

KLEIJNEN, J. P. C.; GAURY, E. G. A. Short-term robustness of production management systems: A case study. European Journal of Operational Research, v. 148, n. 2, p. 452-465, 2003. http://dx.doi.org/10.1016/ S0377-2217(02)00437-X

LAGE JUNIOR, M.; GODINHO FILHO, M. Adaptações ao sistema KANBAN: revisão, classificação, análise e avaliação. Gestão \& Produção, v. 15, n. 1, 2008.

MACCARTHY, B. L.; FERNANDES, F. C. F. A multidimensional classification of production systems for the design and selection of production planning 
and control systems. Production Planning \& Control, v. 11, n. 5, p. 481-496, 2000. http://dx.doi. org/10.1080/09537280050051988

MUKCSTADT, J. A.; TAYUR, S. R. A comparison of alternative KANBAN control mechanism: I. Background and structural results. IIE Transactions, v. 27 , n. 2 , p. 140-150, 1995. http://dx.doi. org/10.1080/07408179508936726

OHNO, T. O Sistema Toyota de Produção - Além da produção em larga escala. Porto Alegre: Editora Bookman, 1997.

SHARMA, S.; AGRAWAL, N. Selection of a pull production control policy under different demand situations for a manufacturing system by AHP algorithm. Computers and Operations Research, v. 36, n. 5, p. 16221632, 2009. http://dx.doi.org/10.1016/j.cor.2008.03.006 SHINGO, S. O Sistema Toyota de Produção - Do ponto de vista da Engenharia de Produção. Porto Alegre: Editora Bookman, 1996.

SPEARMAN, M. L.; WOODRUFF, D. L.; HOPP, W. J. CONWIP - a pull alternative to KANBAN. International Journal of Production Research, v. 28, n. 5, p. 879-894, 1990. http://dx.doi. org/10.1080/00207549008942761

YIN, R. K. Case study research, design and methods. London: Sage Publications, 2003. 
